\title{
Satellite retrieval of the liquid water fraction in tropical clouds between -20 and $-38^{\circ} \mathrm{C}$
}

\author{
D. L. Mitchell ${ }^{1}$ and R. P. d'Entremont ${ }^{2}$ \\ ${ }^{1}$ Desert Research Institute, 2215 Raggio Parkway, Reno, Nevada 89512-1095, USA \\ ${ }^{2}$ Atmospheric and Environmental Research, Inc., 131 Hartwell Ave., Lexington, Massachusetts 02421-3126, USA \\ Correspondence to: D. L. Mitchell (david.mitchell@dri.edu)
}

Received: 8 November 2011 - Published in Atmos. Meas. Tech. Discuss.: 20 December 2011

Revised: 7 June 2012 - Accepted: 12 June 2012 - Published: 18 July 2012

\begin{abstract}
This study describes a satellite remote sensing method for directly retrieving the liquid water fraction in mixed phase clouds, and appears unique in this respect. The method uses MODIS split-window channels for retrieving the liquid fraction from cold clouds where the liquid water fraction is less than $50 \%$ of the total condensate. This makes use of the observation that clouds only containing ice exhibit effective 12-to-11 $\mu \mathrm{m}$ absorption optical thickness ratios $\left(\beta_{\text {eff }}\right)$ that are quasi-constant with retrieved cloud temperature $T$. This observation was made possible by using two $\mathrm{CO}_{2}$ channels to retrieve $T$ and then using the 12 and $11 \mu \mathrm{m}$ channels to retrieve emissivities and $\beta_{\text {eff. Thus }}$ for $T<-40^{\circ} \mathrm{C}, \beta_{\text {eff }}$ is constant, but for $T>-40^{\circ} \mathrm{C}, \beta_{\text {eff }}$ slowly increases due to the presence of liquid water, revealing mean liquid fractions of $\sim 10 \%$ around $-22{ }^{\circ} \mathrm{C}$ from tropical clouds identified as cirrus by the cloud mask. However, the uncertainties for these retrievals are large, and extensive in situ measurements are needed to refine and validate these retrievals. Such liquid levels are shown to reduce the cloud effective diameter $D_{\mathrm{e}}$ such that cloud optical thickness will increase by more than $50 \%$ for a given water path, relative to $D_{\mathrm{e}}$ corresponding to pure ice clouds. Such retrieval information is needed for validation of the cloud microphysics in climate models. Since low levels of liquid water can dominate cloud optical properties, tropical clouds between -25 and $-20^{\circ} \mathrm{C}$ may be susceptible to the first aerosol indirect effect.
\end{abstract}

\section{Introduction}

While much attention has been paid to boundary layer clouds and cirrus clouds, relatively little research has been conducted on mid-level non-precipitating clouds, even though altocumulus and altostratus clouds cover $22 \%$ of the Earth's surface (Warren et al., 1988). Matveev (1984) found that more than $30 \%$ of the clouds between -8 and $-26^{\circ} \mathrm{C}$ were mixed phase. In a detailed field study of mixed phase clouds associated with frontal systems (Korolev et al., 2003), such clouds tended to be predominantly liquid or ice, rarely having comparable fractions of ice and liquid. Comparisons with other field studies revealed that the ice fraction (relative to the total water content) varies widely for a given temperature.

Many studies have failed to find a relationship between cloud phase and temperature (Hobbs and Rangno, 1985; Heymsfield et al., 1991; Lawson et al., 2001; Pinto et al., 2001; Fleishauer et al., 2002; Korolev et al., 2003). Hobbs and Rangno (1998) found that cloud phase was most related to cloud age.

Progress has been made in recent years regarding the ground-based remote sensing of mixed phase clouds, especially in the Arctic where clouds are often mixed phase (Curry et al., 1996). For example, an Arctic mixed phase cloud algorithm has been developed for distinguishing cloud radar Doppler spectra into liquid and ice components (Shupe et al., 2004). Optically thin (visible optical thickness $<6$ ), single layer, Arctic, mixed phase clouds have been characterized in terms of their optical thickness, their ice water fraction, and the effective diameter for water and ice particles using high-resolution infrared radiance and lidar cloud boundary observations (Turner, 2005). Still needed are retrievals 
that can simultaneously characterize the water phase, liquid water content (LWC) and ice water content (IWC), and the effective particle size $D_{\mathrm{e}}$ for water and ice at all altitudes.

Recent progress has also been made regarding the satellite remote sensing of mixed phase clouds, due primarily to the A-train satellite constellation containing the CALIPSO (Cloud-Aerosol Lidar Pathfinder Satellite Observations) satellite with its CALIOP (Cloud-Aerosol Lidar with Orthogonal Polarization) lidar that measures the depolarization of the cloud elements. The depolarization ratio is used to estimate the thermodynamic phase of the cloud particles. Satellite remote sensing studies have detected liquid water between -20 and $-36{ }^{\circ} \mathrm{C}$ at all latitudes (Yoshida et al., 2010; Hu et al., 2010), compiling global statistics on the frequency of occurrence of these mixed phase clouds, as well as the temperature dependence of their liquid water content and path. However, these studies did not retrieve an estimate of the mean liquid water fraction in a cloud field, which is the goal of this study. This combined knowledge should be very helpful for improving cloud-climate feedbacks in global climate models (Hu et al., 2010; Li and Le Treut, 1992).

In general, the liquid fraction in Arctic mixed phase clouds exceeds $40 \%$ (Zhao and Wang, 2010). Due to the relatively high projected area of cloud water droplets relative to ice crystals (per unit mass) and the noted liquid fraction, the liquid phase governs the optical properties of Arctic mixed phase clouds (Shupe and Intrieri, 2004). Thus, the ice phase in these clouds bears significance to the cloud life cycle (i.e., relatively high fall speeds of ice particles accelerate the removal of condensate from the cloud), but it has a relatively weak impact on the cloud optical properties.

A different situation may exist for cold clouds containing low levels of liquid water. In this case, the presence of liquid may have little effect on the cloud life cycle, but it would have a large impact on the cloud optical properties. This is because a small increase in the cloud liquid fraction results in a large increase in the projected area of the size distribution of water and ice particles, provided the liquid fraction is small relative to the total condensate.

This study describes a satellite remote sensing method for retrieving the liquid water fraction from cold clouds ( $\leq$ $-20^{\circ} \mathrm{C}$ ) where the liquid fraction is below $50 \%$. Low levels of liquid coexisting with ice (or predominately liquid clouds coexisting with ice clouds) need to be quantified in order to realistically describe the radiative properties of these clouds in global climate models. This study demonstrates that the liquid water fraction is physically related to the absorption optical thickness ratio at 11 and $12 \mu \mathrm{m}$ (the so-called thermal infrared "split window" region), and how this ratio can be related to cloud temperature. This paper is organized by presenting the cloud temperature/emissivity retrieval methodology in Sect. 2, followed by a description of the liquid fraction retrieval concept in Sect. 3. After describing the microphysics retrieval algorithm in Sect. 4, results and an uncertainty analysis are presented in Sect. 5. The dependence of cloud optics on the retrieved liquid water fraction is given in Sect. 6, and a summary is given in Sect. 7.

\section{Satellite observations of the absorption optical thickness ratio}

The approach we take here to retrieve split-window emissivities is first to use the 13.3 and 14.2- $\mu \mathrm{m}$ carbon-dioxide channels of the Moderate Resolution Imaging Spectroradiometer (MODIS) to retrieve cloud effective temperature. Once the cloud temperature is retrieved, we exploit the thermalinfrared (TIR) window channels at 11 and $12 \mu \mathrm{m}$ to obtain the cloud emissivities. The design of our retrieval algorithm requires first an accurate model of the infrared radiative transfer in clear and cloudy atmospheres, described as follows.

The satellite-observed infrared upwelling radiance $I_{\text {TOA }}$ for a non-scattering atmosphere in local thermodynamic equilibrium is expressed as

$$
\begin{aligned}
I_{\mathrm{TOA}} & =\varepsilon_{\mathrm{SFC}} B\left(\lambda, T_{\mathrm{SFC}}\right) \tau_{\mathrm{ATM}}+\int_{\tau_{\mathrm{ATM}}}^{1} B(\lambda, T) d \tau \\
& +\left(1-\varepsilon_{\mathrm{SFC}}\right) \tau_{\mathrm{ATM}} \int_{\tau_{\mathrm{ATM}}^{*}}^{1} B(\lambda, T) d \tau^{*},
\end{aligned}
$$

where $\varepsilon_{\mathrm{SFC}}$ is the TIR surface emissivity, $B$ is the Planck function, $\lambda$ is wavelength, $\tau$ is the upward atmospheric transmittance profile (from top of atmosphere (TOA) down to some level), and $\tau^{*}$ is the downward transmittance (from the surface up to some level). Atmospheric transmittance for the path between TOA and the Earth's surface is denoted by $\tau_{\mathrm{ATM}}$. In general $\tau \neq \tau^{*}$, but note that $\tau_{\mathrm{ATM}}=\tau_{\mathrm{ATM}}^{*}$ since the path from space to the surface and vice versa is the same, regardless of direction. The first term on the right side of this equation denotes the contribution to the satellite-observed radiance from the Earth's surface. The second term is the upwelling surface and atmospheric energy that is absorbed by the atmosphere and re-emitted to space at its own temperature. The third term represents downwelling atmospheric energy that is reflected to space by the Earth's surface.

\subsection{Practical considerations}

The upwelling radiance prescribed by Eq. (1) has differing terms of dominance for the split-window and carbon-dioxide portions of the spectrum. In the window channels, the surface term (the first term on the right) is dominant; for the $\mathrm{CO}_{2} \mathrm{ab}$ sorption bands, it is the second (middle) term. However, in both cases it is seen that uncertainties in surface emissivity, skin temperature, the atmospheric temperature and water vapor profiles (upon which the transmittances depend) all have an influence on the absolute accuracy of modeled radiances.

In an effort to minimize the impact of these uncertainties on the $I_{\mathrm{TOA}}$ calculations, we have restricted our study 
to over-ocean pixels. For the most part, sea surface temperatures (SSTs) are retrieved directly from satellite observations. SST changes have characteristic time scales on the order of several days. Additionally, they have a small diurnal variation. Finally, accurate ocean-surface models exist that predict emissivity as a function of view angle and ocean-surface wind speed (e.g., Nalli et al., 2008). In contrast to the ocean, land-surface temperatures have a strong diurnal variation that is difficult to capture from low temporal resolution satellite observations (such as MODIS - i.e., twice daily). Additionally, for the purpose of cloud retrievals using window-band radiances, there are no surface temperature observations for the cloudy pixels.

For the clear atmosphere over ocean surfaces, we prescribe all of the terms in Eq. (1) for a given satellite pixel with coincident numerical weather prediction (NWP) atmospheric profiles of pressure, temperature and water vapor (for $\tau$ and $T(\tau))$. We gather these NWP profiles from the Global Forecast System (GFS) maintained by the National Centers for Environmental Prediction (NCEP). GFS also contains a timely sea-surface temperature analysis (for $T_{\mathrm{SFC}}$ ). Finally, we employ the ocean-surface emissivity model of Nalli et al. (2008) for $\varepsilon_{\mathrm{SFC}}$. With atmospheric profiles in hand, we compute the atmospheric optical thicknesses $\delta(s)$ and transmittances $\tau=e^{-\int \delta(s) d s}$ for any given atmospheric path $d s$ using the optimal spectral sampling (OSS) model of Moncet et al. (2004).

\subsection{Retrieving cloud temperature and emissivity}

Now when a "flat-slab" cloud (common in the retrieval literature; see, for example, Inoue, 1985; Parol et al., 1991) is introduced into the pixel, the atmospheric optical thickness $\delta_{\mathrm{TOT}}=\delta_{\mathrm{ATM}}+\delta_{\mathrm{CLD}}$ contains both a clear and a cloudy component in the cloudy layer. Once the cloud physical temperature and absorption optical thickness are prescribed, it is possible to re-estimate the upwelling infrared radiance using Eq. (1) for a cloudy-atmosphere by adjusting the clearatmosphere optical thickness - and subsequently the corresponding transmittance profile - for the cloudy condition.

The next logical step is to select as the cloud retrieval those cloud thermodynamic and radiative properties that yield simultaneously the closest match - in a least-squares sense between satellite-observed brightness temperatures $T_{\mathrm{OBS}}$ and those predicted by Eq. (1), namely $T_{\mathrm{TOA}}=B^{-1}\left(I_{\mathrm{TOA}}\right)$. Typically, the cloud infrared retrieval problem is posed in terms of at least these two unknowns: cloud temperature and absorption optical thickness (which is related to the ratio of cloud-water path and particle effective size, neither of which are the aim of this study). Thus, Eq. (1) requires two pieces of cloud information to compute one cloudy radiance, implying that the retrieval problem must somehow be mathematically constrained since there are two unknowns and only one known. At this point, a second radiance can be introduced, seemingly matching now the number of unknown and known variables. However, the introduction of a new wavelength brings in another variable in the form of a new wavelength-dependent optical thickness, leaving three unknowns and only two knowns. The conventional approach out of this conundrum is to find a relationship between the cloud emissivities across the two chosen wavelengths to obtain closure from a mathematical viewpoint (e.g., see Inoue, 1985; Parol et al., 1991; Giraud et al., 1997).

Such a relation exists between ice-cloud emissivities at 13.3 and $14.2 \mu \mathrm{m}$. Thus, we use radiance measurements in two of the MODIS carbon dioxide channels at 13.3 and $14.2 \mu \mathrm{m}$, respectively, referred to here as channels $\mathrm{A}$ and B. For bulk ice, the real refractive index, $n_{\mathrm{r}}$, at 13.3 and $14.2 \mu \mathrm{m}$ is 1.52 and 1.58 respectively, indicating the absorption contribution from photon tunneling (i.e., wave resonance) is almost the same across these channels (Mitchell, 2000; Mitchell et al., 2010). The imaginary index $n_{\mathrm{i}}$ is 0.355 and 0.246, respectively, generally yielding an ice particle size distribution (PSD) absorption efficiency $Q_{\text {abs }} \approx 1.0$ for each wavelength when tunneling is neglected (Mitchell et al., 2010). This is to say that all radiation incident on the particle cross section is absorbed. Given the approximately equal absorption contributions from tunneling, the combined effects of tunneling and Beer's-Law absorption render approximately equal absorption optical thicknesses in each channel for a given PSD or effective diameter $D_{\mathrm{e}}$. This is shown by the solid curves in Fig. 1 , where $Q_{\text {abs }}$ for these two $\mathrm{CO}_{2}$ absorption channels is plotted as a function of $D_{\mathrm{e}}$ (as defined in Mitchell, 2002). Note that $Q_{\mathrm{abs}}=\beta_{\mathrm{abs}} / A_{\mathrm{PSD}}$, where $\beta_{\mathrm{abs}}$ is the volume absorption coefficient and $A_{\mathrm{PSD}}$ is the projected area of the PSD. Using the ice particle area- and massdimension relationships and the tropical anvil PSD scheme described in Mitchell et al. (2010), Fig. 1 shows that $Q_{\text {abs }}$ is approximately equal in each channel for $D_{\mathrm{e}}>27 \mu \mathrm{m}$ and diverges for smaller $D_{\mathrm{e}}$ due to volume-dependent absorption (Pollack and Cuzzi, 1980).

If the absorption efficiencies are nearly equal, then the absorption optical thicknesses in these two channels are equal to a good approximation. For example, for $\delta_{\mathrm{CLD}, \mathrm{A}}=$ $\{0.105,0.358,0.693,1.204\}$, the corresponding $\delta_{\mathrm{CLD}, \mathrm{B}}=$ $\{0.106,0.360,0.700,1.216\}$. This indicates that the 13.3 and $14.2-\mu \mathrm{m}$ cloud emissivities will be nearly equal. Using the modified anomalous diffraction model of Mitchell (2002), computations for an effective diameter of $80 \mu \mathrm{m}$ reveal that when $\varepsilon_{\mathrm{A}}=\{0.1,0.3,0.5,0.7\}$, the corresponding $\varepsilon_{\mathrm{B}}=$ $\{0.1009,0.3025,0.5035,0.7036\}$. Hence, we assume that they are equal, so that no new unknowns are introduced into the two-equation system when a second $\mathrm{CO}_{2}$-channel radiance observation is added. Now we can write Eq. (1) for two channels, yielding two equations in two unknowns: cloud temperature and 13.3- $\mu \mathrm{m}$ cloud absorption optical thickness.

Before proceeding, we acknowledge that the assumption of equal emissivities has with it the potential to introduce errors in the retrieved cloud temperature. To test retrieval sensitivity, we computed the theoretically expected $I_{\mathrm{TOA}}$ at the 


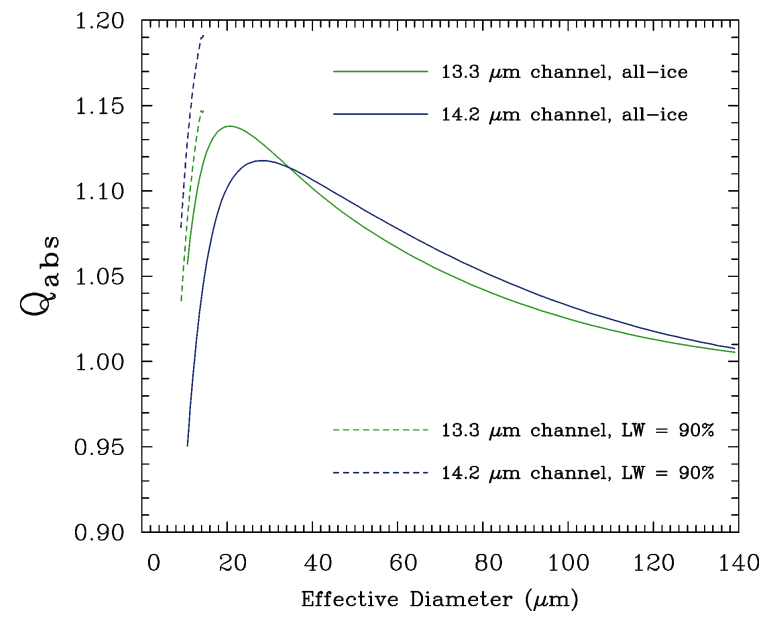

Fig. 1. Testing the temperature retrieval for all-ice and primarily liquid water $(\mathrm{LW})$ conditions over a broad range of ice phase $D_{\mathrm{e}}$. $Q_{\text {abs }}$ is the area-weighted absorption efficiency of an ice particle size distribution (PSD), calculated here for two of the MODIS $\mathrm{CO}_{2}$ channels. See text for details.

two wavelengths for a large range of cloud conditions and assuming non-equal absorption efficiencies (as prescribed by the MADA model of Mitchell, 2002). We then performed a least-squares retrieval analysis sensitivity with the assumption of equal absorption efficiency (equal emissivity). Figure 2a shows that the incurred cloud temperature-retrieval error - again, due solely to the equal-emissivity assumption - is usually less than $0.1 \mathrm{~K}$ over a broad range of all-ice cirrus conditions. The temperature errors result from the fact that $Q_{\text {abs }}$ is not exactly the same in the two $\mathrm{CO}_{2}$ channels; nonetheless, these errors are always less than $0.14 \mathrm{~K}$.

For liquid water clouds, the relative change in $n_{\mathrm{r}}$ (which determines the strength of tunneling contributions) is somewhat greater than for ice at these wavelengths (see Fig. 1 in Mitchell et al., 2010). Since $n_{\mathrm{i}}$ is greater than 0.325 in both carbon-dioxide channels, $Q_{\text {abs }}$ without tunneling will be $\sim 1.0$ for both wavelengths. The combined effects produce a larger but still modest difference in $Q_{\text {abs }}$ shown in Fig. 1 (dashed curves), based on a mean cloud droplet diameter of $10 \mu \mathrm{m}$ and the same ice microphysical assumptions used above. The small range of $D_{\mathrm{e}}$ is due to the liquid water fraction being $90 \%$, even though $D_{\mathrm{e}}$ for the ice phase extends to $139 \mu \mathrm{m}$. Figure $2 \mathrm{~b}$ is like Fig. 2a but examines the condition when the liquid water fraction is $90 \%$. The retrieved temperature errors are less than $0.14 \mathrm{~K}$ at cloud temperatures above $233 \mathrm{~K}$ where liquid water can actually exist. Under conditions where the percentage of MODIS pixels associated with liquid or mixed phase cloud is low (as reported in Sect. 5), the retrieved mean cloud temperature errors will be less than those in Fig. 2b. Note that the temperature error decreases with decreasing liquid fraction. Thus, our coupled cloud temperature/emissivity retrieval appears quite

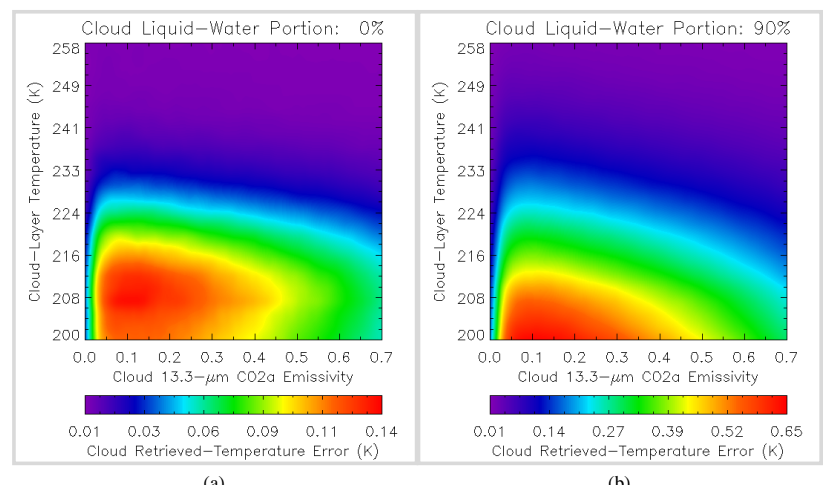

(a)

(b)

Fig. 2. Retrieved temperature error incurred by invoking the equalemissivity assumption for (a) glaciated clouds and (b) mixed phase clouds having $90 \%$ liquid water. Clouds are described by their midlayer temperature and their emissivity at $13.3 \mu \mathrm{m}$, with colors showing the temperature error in the retrieval. See text for details.

insensitive to the $\mathrm{CO}_{2}$ equal-emissivity assumption over the temperature ranges we encountered in the MODIS datasets.

Cloud effective-temperature retrievals using the two $\mathrm{CO}_{2}$ channels were converted to height using collocated NWP temperature profiles, and then compared with MODIS-subtrack observations of cloud vertical extent from CALIPSO. For 22 July, we obtained effective heights in the range $11-13 \mathrm{~km}$, and lidar revealed the vertical extent of the cloud as $10-15 \mathrm{~km}$. For 5 August, our satellite-retrieved heights were in the range $11-14 \mathrm{~km}$, and lidar reported clouds in the range $8-15 \mathrm{~km}$.

\subsection{Cloud emissivity retrievals in the split window}

With the cloud physical temperature now in hand, we continue on to retrieve cloud emissivities in the split window channels at 11 and $12 \mu \mathrm{m}$. In these window channels, a simple non-scattering approach to the radiative transfer can be used, assuming emission/transmission of above-cloud water vapor is negligible. Assuming nadir viewing and cloud-filled pixels, for each infrared channel we can write

$I_{\mathrm{OBS}}=(1-\varepsilon) I_{\mathrm{CLR}}+\varepsilon B\left(T_{\mathrm{CLD}}\right)$,

where $I_{\mathrm{OBS}}$ is the satellite-observed radiance, $I_{\mathrm{CLR}}$ is the clear-atmosphere radiance, $\varepsilon$ is the (unknown) cloud emissivity and $B\left(T_{\mathrm{CLD}}\right)$ is the Planck function evaluated at cloud temperature $T_{\mathrm{CLD}}$ (previously obtained from the $\mathrm{CO}_{2}$ channels).

Recall in Sect. 2.1 that the clear-atmosphere radiances are estimated using GFS prescriptions of SST, the atmospheric temperature and water-vapor profiles, and the oceansurface emissivity model of Nalli et al. (2008). Using the multispectral cloud-detection tests outlined in Appendix A, single-layer clouds classified as cirrus are detected within the MODIS image. We then compared the MODIS split-window over-ocean observations of the clear-atmosphere brightness 
temperatures with those at 11 and $12 \mu \mathrm{m}$ that were computed using Eq. (1). The resulting error distributions were Gaussian in shape, with mean errors between -0.9 and $-1.3 \mathrm{~K}$, and standard deviations of $1 \mathrm{~K}$. This yields confidence in estimating the $I_{\mathrm{CLR}}$ term in Eq. (2).

With accurate estimates of $I_{\mathrm{CLR}}$ in hand, we solve for $\varepsilon_{\mathrm{CLD}}$ as the only unknown in Eq. (2):

$\varepsilon(11 \mu \mathrm{m})=\frac{I_{11, \mathrm{OBS}}-I_{11, \mathrm{CLR}}}{B_{11}\left(T_{\mathrm{CLD}}\right)-I_{11, \mathrm{CLR}}}$

with a similar expression for $\varepsilon(12 \mu \mathrm{m})$. Corresponding cloud absorption optical thicknesses $\delta_{\lambda}$ at each wavelength are obtained using

$\delta_{\lambda}=-\ln \left(1-\varepsilon_{\lambda}\right)$.

It is important at this point to discuss briefly any emissivity errors that are taken up into the split-window emissivity retrievals by assuming the maximum mixed-phase cloud-temperature error of $0.65 \mathrm{~K}$ shown in Fig. 2b. Assuming a cloud layer temperature of $240 \mathrm{~K}$, an ocean-surface temperature of $298 \mathrm{~K}$ and a cloud with "true" emissivity $\varepsilon(11 \mu \mathrm{m})=\{0.1,0.3,0.5,0.7\}$, then the corresponding retrieved emissivities are $\{0.1008,0.3026,0.5039,0.7055\}$, each within over $99 \%$ of their "true" values.

A brief mention is made here concerning the issue of partial cloud cover within an individual MODIS pixel. Wherever the term $\varepsilon$ appears in Eq. (2), it is modified by the cloud fraction $n$, namely $I_{\mathrm{OBS}}=(1-n \varepsilon) I_{\mathrm{CLR}}+$ $n \varepsilon B\left(T_{\mathrm{CLD}}\right)$, where $0 \leq n \leq 1$. This result again assumes no scattering. The right side of Eq. (3) remains unchanged, but the left side is modified by cloud fraction: $n \varepsilon$ $(11 \mu \mathrm{m})=\left(I_{11, \mathrm{OBS}}-I_{11, \mathrm{CLR}}\right) /\left(B_{11}\left(T_{\mathrm{CLD}}\right)-I_{11, \mathrm{CLR}}\right)$. Ignoring cloud fraction within each pixel (i.e., assuming as we do in this study that $n=1$ ) generally leads to a retrieved emissivity that is too low and, subsequently, an effective temperature that is too high. There is no easy way to include cloud fraction as an explicit retrievable, and so we choose $n=1$ with the expectation that the high clouds sampled completely fill the field of view; such an assumption is reasonable whenever cirrus shields are extensive, as they are in this study (see Figs. 3 and 4).

\subsection{Effective absorption optical thickness ratio}

The parameter of interest for inferring cloud microphysical attributes is the ratio of the absorption optical thicknesses at 12 and $11 \mu \mathrm{m}$, defined in the non-scattering case as

$\beta=\delta_{12} / \delta_{11}$,

which, for the flat-slab assumption, works out to be simply the ratio $Q_{12} / Q_{11}$ of PSD absorption efficiencies at the two wavelengths. Absorption efficiency is strongly dependent on cloud microphysical properties (e.g., ice particle shape and size), and so it is sensible that their ratio is a valuable metric

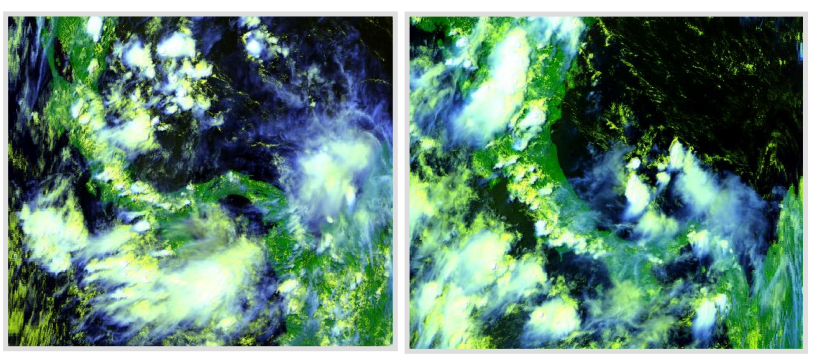

Fig. 3. Cloud scenes over Costa Rica on 22 July (left panel) and 5 August 2007 (right panel) during the NASA TC4 experiment. Blue colors indicate cirrus clouds, white is deep convection, and yellow indicates liquid water clouds. These color composites were generated by mapping the $0.47,0.86$ and $11-\mu \mathrm{m}$ channels into the red, green and blue color intensities, respectively. For more details see Appendix A.

of cloud microphysics. What is retrieved from satellite radiances is not truly $\beta$ but an effective $\beta$, denoted $\beta_{\text {eff, that in- }}$ cludes scattering effects. To calculate this $\beta_{\text {eff }}$ in the retrieval algorithm (which, to be clear, is $\beta$ adjusted for scattering effects), we use the method described in Parol et al. (1991) and Mitchell et al. (2010):

$\beta_{\text {eff }}=Q_{\text {abs,eff }}(12 \mu \mathrm{m}) / Q_{\text {abs,eff }}(11 \mu \mathrm{m})$

and

$Q_{\mathrm{abs}, \mathrm{eff}}=Q_{\mathrm{abs}}\left(1-\omega_{o} g\right) /\left(1-\omega_{o}\right)$,

where $g$ is the PSD asymmetry parameter and $\omega_{o}$ is the single scattering albedo of the PSD. Note that when all radiation is scattered in the forward direction (approached in nonscattering conditions), $g=1$ and $Q_{\mathrm{abs}, \text { eff }}=Q_{\mathrm{abs}}$. In the retrieval algorithm, $\beta_{\text {eff }}$ is calculated from Eq. (6) using the $g$ parameterization given in Yang et al. (2005), which is parameterized in terms of $D_{\mathrm{e}}$ and assumes a certain combination of ice particle shapes. While this shape assumption affects the wave resonance contribution to absorption, ice particle shape for a given $D_{\mathrm{e}}$ has a very weak impact on $g$ at thermal wavelengths where $g$ depends primarily on forward scattering as determined by the particle's area cross-section (van de Hulst, 1981). The effective emissivity is related to $\beta_{\text {eff }}$ as described in Inoue (1985):

$\varepsilon_{\mathrm{eff}}(12 \mu \mathrm{m})=1-\left[1-\varepsilon_{\mathrm{eff}}(11 \mu \mathrm{m})\right]^{\beta_{\mathrm{eff}}}$.

The optical properties of both liquid water clouds (Mitchell, 2000) and ice clouds (Mitchell, 2002) were determined using the modified anomalous diffraction approximation or MADA. MADA yields reasonably accurate and rapid calculations suitable for large volumes of satellite data and rigorously accounts for size distribution and ice crystal shape effects. For example, MADA and Mie theory agree within $10 \%$ for liquid water clouds, while laboratory ice cloud extinction measurements were predicted by MADA with $3.0 \%$ 

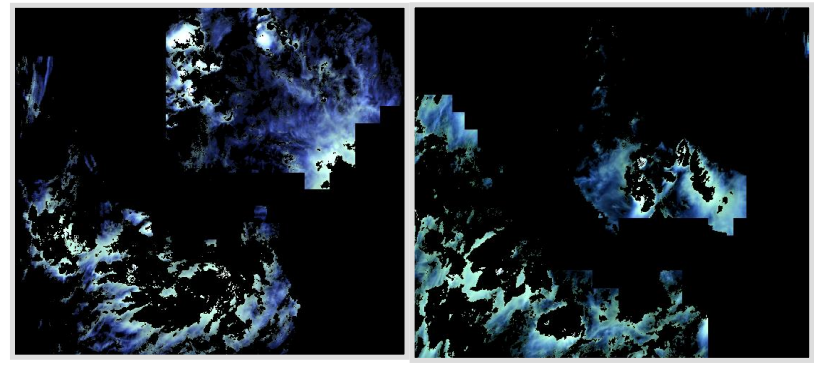

Fig. 4. Same as Fig. 3 except a cloud mask was applied to show only cirrus clouds (white-to-bluish colors).

differences on average over the size parameter range of 2 to 22. MADA errors relative to the finite-difference timedomain (FDTD) method for ice PSDs regarding $Q_{\text {abs }}$ were no greater than $15 \%$ over a wavelength range 3-100 $\mu \mathrm{m}$ for six ice particle shapes (Mitchell et al., 2006).

In this paper, we extend the $\beta_{\text {eff }}$ measurements in Mitchell et al. (2010) to include higher temperatures between -35 and $-20^{\circ} \mathrm{C}$. Two cloud fields observed off Costa Rica on 22 July and 5 August 2007 are evaluated that correspond to clouds studied during the Tropical Composition, Cloud and Climate Coupling (TC4) field campaign. These cloud scenes are from the MODIS instrument and cover areas of roughly 65415 and $41925 \mathrm{~km}^{2}$, respectively, assuming $1 \mathrm{~km}^{2}$ per infrared MODIS pixel. Color composites of the cloud scenes for 22 July and 5 August 2007 are shown in Fig. 3, where yellow indicates low water cloud, white deep convective cloud and blue cirrus cloud. Figure 4 shows the same scenes, but a cloud mask has been applied, showing only the clouds identified as cirrus clouds. In this way, the identified cirrus clouds were isolated and evaluated in each scene. All retrievals were over ocean and correspond to single-layer clouds. Cloud emissivities, or $\varepsilon$, were filtered such that $\varepsilon(11 \mu \mathrm{m}) \leq 0.70$ for all pixels retrieved in this study. This was done so that all levels of the semi-transparent cloud contribute to the observed radiances, and the radiances depend primarily on the cloud microphysics, as described in Mitchell et al. (2010). Retrievals of $\beta_{\text {eff }}$ for these two days are shown in Fig. 5 as a function of retrieved temperature $T$. Retrievals of $\beta_{\text {eff }}$ were grouped into 13 equally spaced temperature intervals to provide mean $\beta_{\text {eff }}$ values and a standard deviation $(\sigma)$ in $\beta_{\text {eff }}$ for each $T$-interval.

\section{Retrieval Concept}

Figure 5 shows that, between $200 \mathrm{~K}$ and $235 \mathrm{~K}$, mean values of $\beta_{\text {eff }}$ are essentially constant with temperature, but for $T>235 \mathrm{~K}$, the mean $\beta_{\text {eff }}$ increases and rather substantially at the higher temperatures. This same $\beta_{\text {eff }}$ behavior was reported in Giraud et al. (1997) where the retrieved maximum $\beta_{\text {eff }}$ values were related to cloud top temperature, based on 21
AVHRR images of high clouds over the northern Atlantic and Europe. For $T<235 \mathrm{~K}, \beta_{\text {eff }}$ was constant with $T$, while for $T>235 \mathrm{~K}, \beta_{\text {eff }}$ increased, leveling off around $253 \mathrm{~K}$. Subsequent reanalysis of this dataset (Giraud et al., 2001), including one day of coincident POLDER-ATSR2 satellite data, found that the increase in $\beta_{\text {eff }}$ with higher $T$ was due to a change in phase from ice to liquid, although there was no way to quantify the liquid fraction (i.e., the percent liquid to total condensate). Additional support for these findings is presented in Sect. 5.1.

As described in Mitchell et al. (2010), $\beta_{\text {eff }}$ is only sensitive to small cloud particles having maximum dimension $D<\sim$ $60 \mu \mathrm{m}$. The objective of this study is to quantify this liquid fraction by extending the retrieval algorithm of Mitchell et al. (2010) to include mixed phase clouds. This is only possible due to this fortuitous "flat" $T$-dependence of $\beta_{\text {eff }}$ for glaciated (all-ice) conditions. Given that both glaciated and mixed phase conditions are present in a cloud field, relating $\beta_{\text {eff }}$ to $T$ should reveal a "hockey-stick" signature where the deviation from constant $\beta_{\text {eff }}$ that occurs at warmer temperatures should indicate some level of liquid water in the cloud field. The algorithm described next seeks to quantify this level.

\section{Algorithm description}

The retrieval algorithm used here is similar to that used in Mitchell et al. (2010), assuming a bimodal size distribution. But in the previous study, the small mode of the size distribution was comprised of ice crystals, whereas here it is assumed to be completely liquid. Consequently, the refractive indexes applied to the small mode (for calculating optical properties) correspond to liquid water. The large mode ice particle shapes are the same as in the previous study, based on TC4 measurements.

Also similar to Mitchell et al. (2010), this algorithm deals with the average behavior of the microphysics in a cloud scene, and does not address the microphysical properties of a cloud region corresponding to a single MODIS pixel. That is, the retrievals correspond to mean $\beta_{\text {eff }}$ values and their standard deviations $(\sigma)$ for each $T$-interval.

A diagram describing the principle by which the retrieval operates is described in Fig. 6. For tropical anvil clouds, a temperature-dependent ice particle size distribution (PSD) scheme based on anvil clouds sampled during the Central Equatorial Pacific Experiment (CEPEX) is used to represent the ice phase (Ivanova, 2004). The PSD constituting the large particle mode is a gamma function of the form:

$N(D)=N_{o} D^{v} \exp (-\lambda D)$,

where $\lambda$ is the slope parameter, $v$ is the dispersion or width parameter, and $N_{o}$ relates the other two parameters to the PSD number concentration or IWC. A fixed IWC of $10 \mathrm{mg} \mathrm{m}^{-3}$ is assumed in the algorithm (this is arbitrary and 


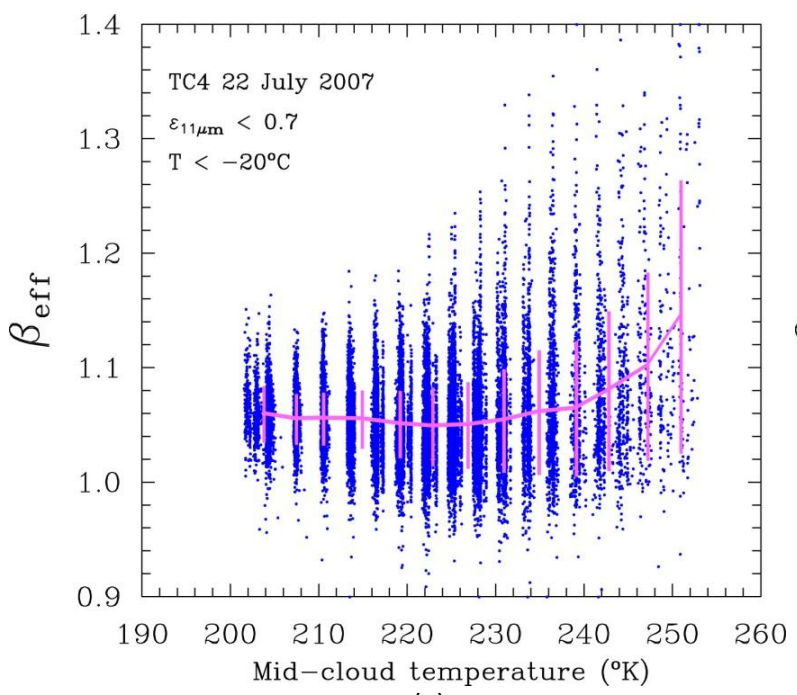

(a)

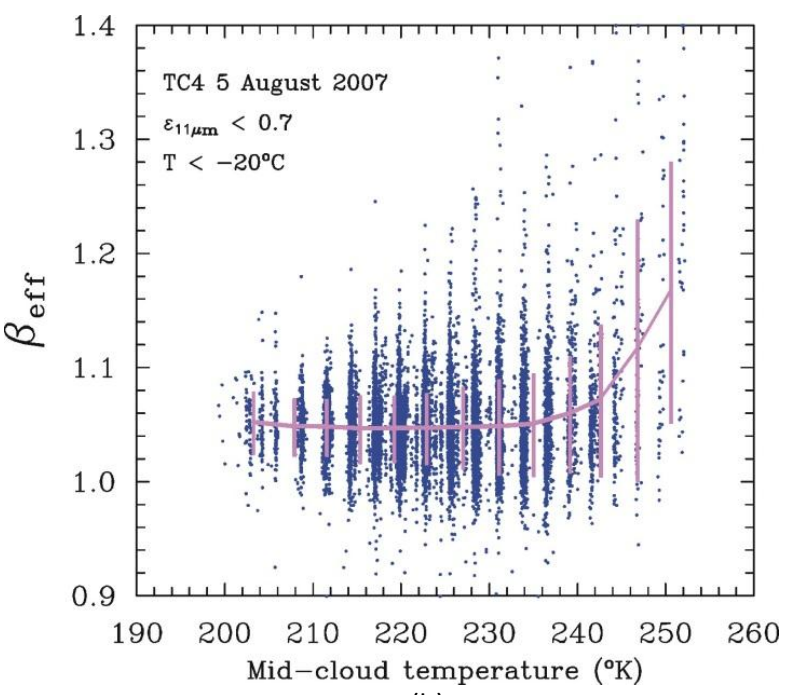

(b)

Fig. 5. Retrievals of the effective absorption optical thickness ratio related to retrieved mid-cloud temperature for (a) the 22 July cloud scene and (b) the 5 August cloud scene. Cloudy pixels were filtered so that only pixels having $11 \mu \mathrm{m}$ emissivities less than 0.7 and temperatures less than $-20^{\circ} \mathrm{C}$ were used.

does not affect the retrieval). Retrieved cloud temperature specifies $\lambda$ and $v=0$ based on the CEPEX PSD measurements. In a radiative sense, ice particle shape is defined by an ice particle's projected area- and mass-dimension relationships. These power law relationships were derived from TC4 2D-Stereo (2D-S) probe data as described in the appendix of Mitchell et al. (2010) and are used in this retrieval. The small mode of this mixed phase PSD (i.e., the cloud droplet size distribution) is also a gamma function having $v=9$, which is common for liquid water clouds (Mitchell, 2000). The slope $\lambda$ is determined from an assumed droplet size distribution mean diameter $\bar{d}$ :

$\lambda=(v+1) / \bar{d}$.

As discussed later, $\bar{d}$ was inferred to be between 9 and $11 \mu \mathrm{m}$. As described in Mitchell et al. (2010), the value of $\beta_{\text {eff }}$ is calculated by initially assigning negligible liquid water content (LWC) to the small mode and calculating $\beta_{\text {eff }}$ from the bimodal PSD. This is compared with the retrieved value of $\beta_{\text {eff }}$. In mixed phase conditions, the observed $\beta_{\text {eff }}$ will be larger than predicted, and the LWC of the small mode is increased incrementally until the predicted and observed $\beta_{\text {eff }}$ match. This yields the ratio LWC/(IWC + LWC), which is the retrieved liquid water fraction. Since we are dealing with ratios, it does not matter what was initially assumed for the IWC.

The details of how this works are now described. As noted, this retrieval only considers the mean values of $\beta_{\text {eff }}$ and their standard deviations when processing a cloud scene, shown by the pink curves and bars in Fig. 5. Table 1 gives the mean values of $\beta_{\text {eff }}$ for the two case studies based only on the all-ice clouds $\left(-70^{\circ} \mathrm{C}<T<-38^{\circ} \mathrm{C}\right)$. Adjacent to these means is the standard deviation (SD) for each mean. A threshold value

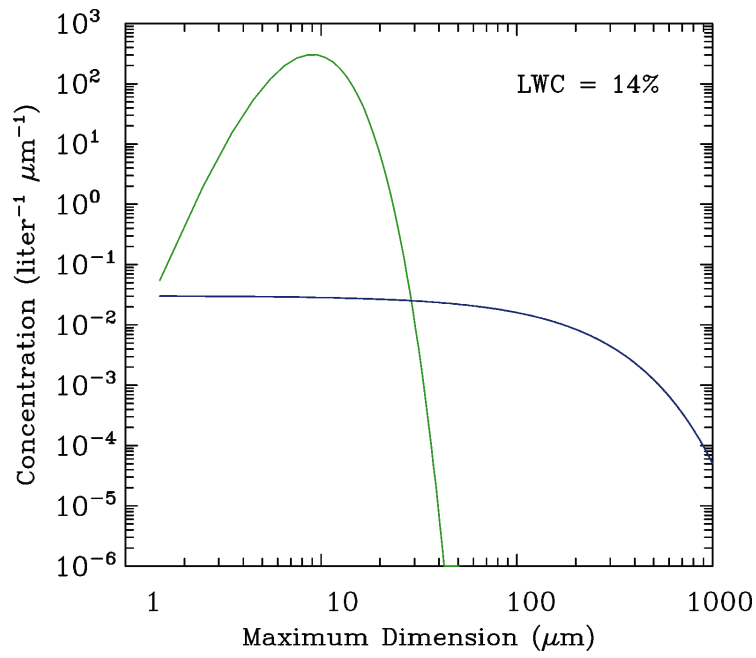

Fig. 6. Algorithm framework with a variable droplet size distribution in green and a temperature-dependent anvil cirrus PSD in blue. The liquid water content (LWC) of the droplet size distribution shown here is $14 \%$ of the total condensate (liquid + ice).

$\beta_{\mathrm{t}}$ equal to the mean $+2(\mathrm{SD})$ is established such that LWC is added to the small mode only when $\beta_{\text {eff }}>\beta_{\mathrm{t}}$. Otherwise the cloud is assumed glaciated.

Mean values of the liquid fraction can be misleading when evaluating the presence of liquid in a cloud scene since they tell nothing about the distribution of liquid fraction on the cloud scale. For this reason, it is important to evaluate the liquid fraction for the positive standard deviations of $\beta_{\mathrm{eff}}$, that is, the quantity $\beta_{\text {eff }}+\sigma$ (i.e., the tops of the pink bars 
Table 1. Mean values of retrieved $\beta_{\text {eff }}$ and $\left(\beta_{\text {eff }}+\sigma\right)$, with corresponding values of their standard deviations (SD) for the two case studies. $\beta_{\text {eff }}$ is the effective 12-to- $11 \mu \mathrm{m}$ absorption optical thickness ratio, and its SD at a given temperature is given by $\sigma$.

\begin{tabular}{lrrrrr}
\hline Date & Temperature Interval $\left({ }^{\circ} \mathrm{C}\right)$ & Mean $\beta_{\text {eff }}$ & SD & Mean $\left(\beta_{\text {eff }}+\sigma\right)$ & SD \\
\hline 22 July 2007 & -69 to -38 & 1.0539 & 0.0042 & 1.0891 & 0.0133 \\
5 August 2007 & -70 to -38 & 1.0474 & 0.0018 & 1.0801 & 0.0080 \\
\hline
\end{tabular}

in Fig. 5) for temperature $T>-38^{\circ} \mathrm{C}$. For $T<-38^{\circ} \mathrm{C}$, the mean value of $\left(\beta_{\text {eff }}+\sigma\right)$ and the $\mathrm{SD}$ of this mean are also shown in Table 1 (right side). For each value of $\left(\beta_{\text {eff }}+\sigma\right)$ for $T>-38^{\circ} \mathrm{C}$, its corresponding liquid fraction was retrieved using the same methodology; a threshold value $\beta_{\mathrm{t}}$ equal to the mean $\left(\beta_{\text {eff }}+\sigma\right)+2$ (SD) (from right side of Table 1$)$ is established such that LWC is added to the small PSD mode only when the algorithm calculated $\beta_{\mathrm{eff}}>\beta_{\mathrm{t}}$. In this way, the liquid water fraction corresponding to each observational $\left(\beta_{\text {eff }}+\sigma\right)$ value is estimated for $T>-38^{\circ} \mathrm{C}$. As evident from Fig. 5, this methodology works best when a large portion of the cloud field corresponds to $T<-38^{\circ} \mathrm{C}$, insuring a good baseline from which to estimate $\beta_{\mathrm{t}}$ values.

Figure 7 demonstrates the dependence of the retrieved liquid water fraction on $\beta_{\text {eff }}$ and the sensitivity of the retrieval on the assumed mean cloud droplet size. It is clear that for liquid fractions more than $50 \%$, this retrieval will not yield accurate estimates of percent liquid water since small changes in $\beta_{\text {eff }}$ result in large changes in liquid fraction. But for liquid fractions $<50 \%$, the retrieval may yield meaningful estimates of the liquid fraction. The retrieval is shown to be sensitive to the assumed cloud droplet diameter, with the lower red curve in Fig. 7 corresponding to $9 \mu \mathrm{m}$ and the upper curve corresponding to $11 \mu \mathrm{m}$. Another cloud droplet size distribution attribute that the retrieval is sensitive to is the droplet dispersion parameter; changing this from 5 to 15 changed the liquid fraction by $\pm 26 \%$. The retrieval is less sensitive to large particle PSD parameters since the wavelengths employed are only sensitive to particles less than $\sim 60 \mu \mathrm{m}$.

The physics of radiation absorption in this mixed-phase retrieval differs from the cirrus cloud PSD retrieval described in Mitchell et al. (2010). For all-ice clouds, changes in the PSD small mode are detected from changes in absorption contributions resulting from wave resonance (i.e., photon tunneling phenomena). For mixed phase clouds, the small mode is comprised of water droplets and absorption/emission depends mostly on the path length of radiation through the cloud droplet and not on wave resonance (see Fig. 1 in Mitchell et al., 2010).

\section{Retrieval results and uncertainties}

Retrievals of the liquid fraction for the two cloud scenes are shown in Fig. 8, with the mean liquid fraction based on the mean $\beta_{\text {eff }}$ over a given temperature interval, and the standard

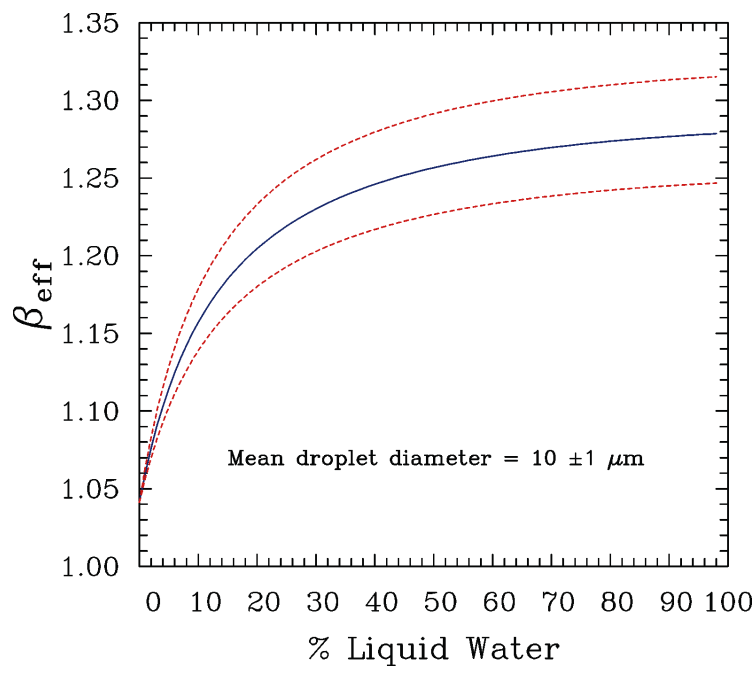

Fig. 7. Dependence of the retrieved liquid water fraction on $\beta_{\text {eff }}$ and the sensitivity of the retrieval on the assumed mean cloud droplet size. The blue curve is for a mean size of $10 \mu \mathrm{m}$, while the two red dashed curves are for mean droplet sizes of 9 (lower) and 11 (upper) $\mu \mathrm{m}$.

deviation corresponding to the mean liquid fraction based on the $\sigma$ corresponding to the mean $\beta_{\text {eff. The }} \bar{d}$ assumed was $10 \mu \mathrm{m}$ and $\nu=9$. Although the mean liquid fractions are low, this technique is very sensitive to low levels of liquid water, as shown in Fig. 7. Liquid fraction standard deviations in Fig. 8 increase with increasing temperature for $T>-40^{\circ} \mathrm{C}$. This may be due to clouds tending to be mostly liquid or mostly ice, but generally not consisting of comparable portions of both liquid and ice (Korolev et al., 2003). Careful inspection of Fig. 5 at the highest temperatures reveals more points associated with the standard deviations than the means (indicating a more polarized phase partitioning), consistent with the observations in Korolev et al. (2003). Liquid fractions greater than $50 \%$ are not reliable, as shown by Fig. 7 . Liquid fraction standard deviation values corresponding to $\sim 60 \%$ and $90 \%$ in Fig. 8 may both indicate cloud conditions that are almost all liquid.

When $\bar{d}$ in the algorithm is changed to $12 \mu \mathrm{m}$ or larger values, for all practical purposes (given the uncertainty), the algorithm predicts $100 \%$ liquid water at temperatures corresponding to -22 and $-26^{\circ} \mathrm{C}$ when $\beta_{\text {eff }}$ equals mean $\beta_{\text {eff }}+\sigma$ for the 5 August cloud scene. However, the value of (mean $\beta_{\text {eff }}+\sigma$ ) at $-26^{\circ} \mathrm{C}$ is clearly less than that at $-22^{\circ} \mathrm{C}$. Thus, 


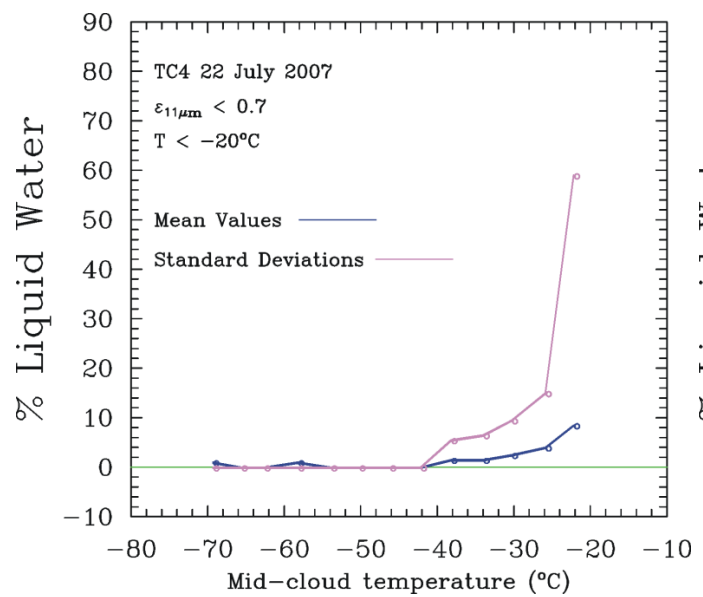

(a)

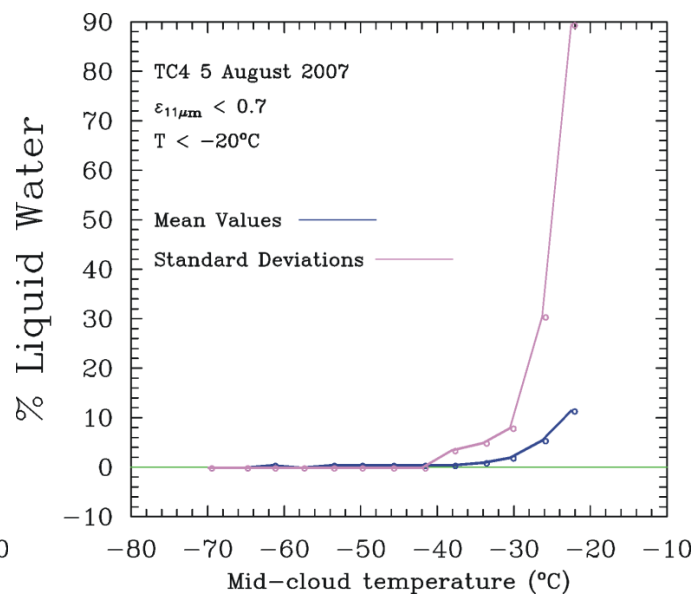

(b)

Fig. 8. Retrieved liquid fraction for clouds identified as single-layer cirrus for the two cloud scenes studied. Both means and standard deviations are plotted against retrieved temperature as described in the text. Cloud emissivities (at $11 \mu \mathrm{m}$ ) and temperatures were less than 0.7 and $-20^{\circ} \mathrm{C}$, respectively.

the algorithm exhibits non-physical behavior for this cloud scene when $\bar{d} \geq 12 \mu \mathrm{m}$. Moreover, in situ observations of mixed phase Arctic clouds (Lawson et al., 2001) during FIRE ACE did not find $\bar{d}<9 \mu \mathrm{m}$. While not definitive, this information allows us to estimate that $\bar{d}$ lies between 9 and $11 \mu \mathrm{m}$ for the 5 August cloud scene, and we assume that the same is true for the 22 July cloud scene. This is why we evaluate the algorithm sensitivity to droplet mean size in Fig. 7 using mean diameters of 9,10 and $11 \mu \mathrm{m}$.

An uncertainty analysis based on varying $\bar{d}$ from 9 to $11 \mu \mathrm{m}$ and $v$ from 5 to 15 is shown in Fig. 9, yielding lower and upper limit estimates for the mean $\beta_{\text {eff }}$ and the mean $\beta_{\text {eff }}+\sigma$ values. The range of the uncertainty of the liquid fraction increases as the retrieved liquid fraction (mean or standard deviation) increases.

\subsection{Liquid water or ice?}

The aircraft cloud microphysical data from TC4 were inspected for the presence of liquid water at temperatures less than $-20^{\circ} \mathrm{C}$, and no evidence of liquid was found (R. P. Lawson, personal communication, 2010). However, neither the TC4 flight plans nor the microphysics data processing algorithm was designed to look for the presence of liquid water (R. P. Lawson, personal communication, 2010). Conversely, recent ground-based and satellite remote sensing studies have detected liquid water between -20 and $-36^{\circ} \mathrm{C}$ in tropical cloud fields (Ansmann et al., 2009; Yoshida et al., 2010; Hu et al., 2010; van Diedenhoven et al., 2012), and in situ measurements in strong updrafts of deep convective clouds have shown sustained liquid water down to $-37.5^{\circ} \mathrm{C}$ (Rosenfeld and Woodley, 2000). Liquid water at these temperatures was almost always detected at the tops of tropical altocumulus during the Saharan Mineral Dust Experiment (Ansmann

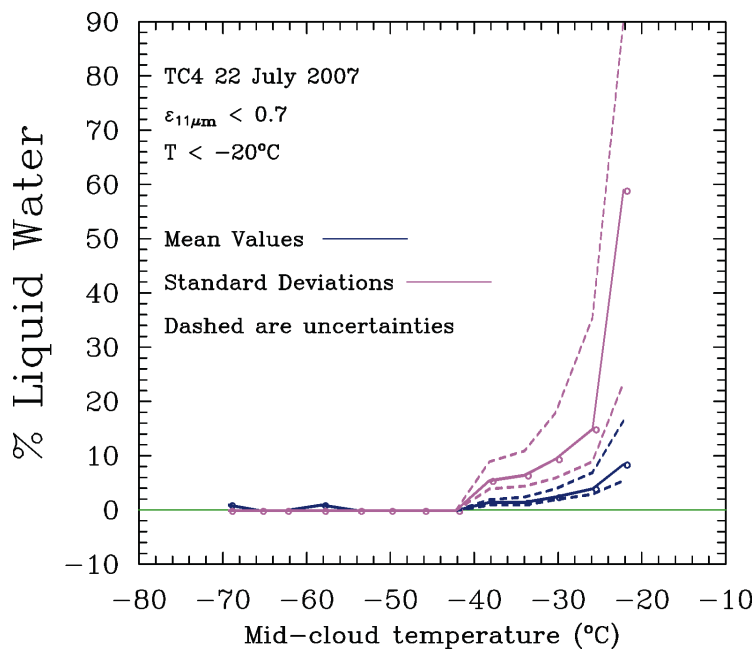

Fig. 9. Uncertainty estimates (dashed) for the means and standard deviations (solid) in Fig. 8a.

et al., 2009). These apparently conflicting results might be reconciled if a small fraction of the cloud field between -20 and $-30^{\circ} \mathrm{C}$ is containing significant liquid water, as the results in Fig. 5 appear to suggest. That is, the odds of a research aircraft sampling liquid water are not good if the spatial coverage and temporal frequency of liquid water are low. Moreover, the data processing algorithm used for TC4 PSD measurements selected only those periods when the PSD median mass dimension and extinction coefficient were relatively stable. Since cloud patches containing liquid would produce relatively unstable microphysical conditions, sampling intervals containing liquid may have been eliminated by the algorithm sample selection criteria. 
A retrieval methodology similar to this one has been used to estimate the PSD of ice clouds (Mitchell et al., 2010). Naturally, the question may be asked "what assurance does one have that $\beta_{\text {eff }}$ at warmer temperatures is not primarily due to small ice crystals?" While it is conceivable that the increase in $\beta_{\text {eff }}$ is due to small ice crystals, we argue that this is very unlikely by applying the retrieval methodology of Mitchell et al. (2010) to the 5 August 2007 case study shown in Fig. 5b. The same assumptions used previously are used here, with ice crystal projected area- and mass-dimension power law relationships based on TC4 data. The anvil cirrus PSD scheme described previously is used here. The mean $\beta_{\text {eff }}$ values in Fig. $5 \mathrm{~b}$ are used in this retrieval that assumes ice-only conditions. A feature of this retrieval is the partitioning of the ice particle number concentration $N$ into two modes: a small mode corresponding to quasi-spherical ice particles with $D<60 \mu \mathrm{m}$ and a larger particle mode containing more complex crystal shapes. The concentration ratio of the small ice crystal mode to the larger particle mode is plotted as a function of cloud temperature in Fig. 10. Ratios $\ll 1$ indicate monomodal PSD, with bimodality becoming clearly apparent for ratios $>\sim 1$. Strong bimodality is manifested for ratios $>10$. The onset of "strong bimodality" as defined here for pure ice clouds is characterized by the peak concentration of the small mode being $10^{2}$ higher than the peak concentration of the large mode. Figure 10 shows that predicted PSDs at temperatures greater than $-30^{\circ} \mathrm{C}$ are strongly bimodal, with $N$ ratios reaching 250 at $-20^{\circ} \mathrm{C}$. Based on the in situ PSD measurements during TC4 (Jensen et al., 2009; Lawson et al., 2010), such extreme bimodality appears unrealistic. Very similar results were obtained for the 22 July case study.

In Fig. $5 b$, note that, at the warmest temperatures, the $\beta_{\text {eff }}$ values are not centered on the mean but rather are clustered on either side of the mean, with many points near the standard deviations. If one applies the Mitchell et al. (2010) retrieval to estimate PSD based on the positive standard deviations of $\beta_{\text {eff }}$ for $-27^{\circ} \mathrm{C}<T<-20^{\circ} \mathrm{C}, N$ ratios range from $\sim 360$ to 4800 , and $N$ ranges from 1.5 to $6.0 \mathrm{~cm}^{-3}$ for an assumed typical IWC of $10 \mathrm{mg} \mathrm{m}^{-3}$. Such ratios appear unrealistic, and such concentrations may also be unrealistic under most conditions (Jensen et al., 2009; Zhao et al., 2010).

The PSDs sampled during TC4 in relatively "fresh" anvil cirrus (attached to convective columns) are shown in Fig. 11 (see Mitchell et al., 2011a, for details). It is seen that the PSDs change from monomodal to bimodal with increasing temperature, changing near $T=-40^{\circ} \mathrm{C}$. A similar shift in modality occurred for aged anvil cirrus but not for in situ cirrus during TC4. Thus, it is possible that the change at $-40^{\circ} \mathrm{C}$ in Fig. 10, from monomodal to bimodal, is initially due to ice-only PSD (note that homogeneous freezing nucleation begins $\sim-40^{\circ} \mathrm{C}$, possibly explaining the change in PSD behavior with higher nucleation rates commencing near $-40^{\circ} \mathrm{C}$ ). However, at much warmer temperatures, the bimodality in Fig. 10 appears too extreme to attribute it to

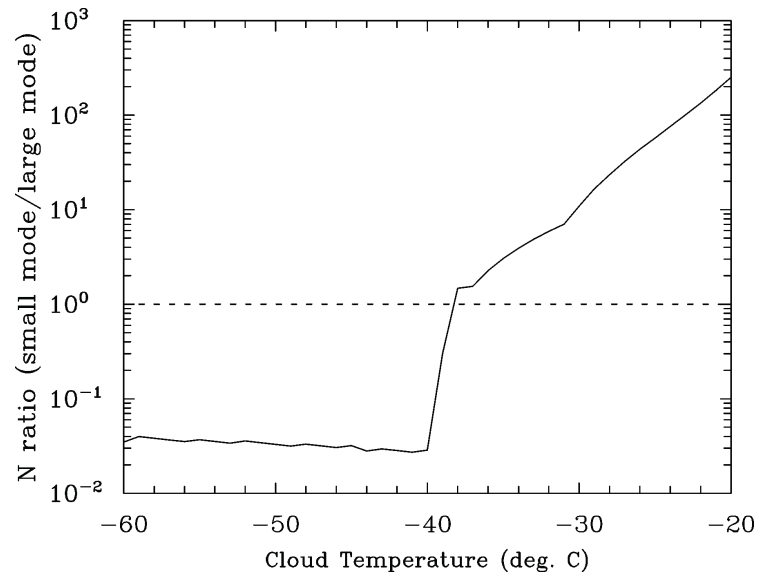

Fig. 10. Retrieval of PSD bimodality for the 5 August 2007 case study, based on the mean $\beta_{\text {eff }}$ values in Fig. $5 \mathrm{~b}$ assuming all-ice conditions. Bimodality is evaluated using the $N$ ratio (ice particle concentration of small mode / large mode) with $N$ ratio $\sim 1$ roughly separating unimodal from bimodal PSDs.

the ice phase only (for reasons described above), and the observed bimodality in Fig. 11 is not that extreme.

Lastly, a split-window remote sensing study (Cooper and Garrett, 2010) found that the fraction of tropical thin cirrus comprised of small ice crystals increased from -40 to $-30^{\circ} \mathrm{C}$. However, based on the results of this study, this may be a consequence of low levels of liquid water rather than small ice crystals. Moreover, the 11 and $12 \mu \mathrm{m}$ split-window method is only sensitive to particles having $D<\sim 60 \mu \mathrm{m}$ and thus the actual PSD may contain significant concentrations of much larger ice particles, with the actual $D_{\mathrm{e}}$ considerably larger than the retrieved $D_{\mathrm{e}}$ if the PSDs are bimodal (Mitchell et al., 2010; Mitchell and d'Entremont, 2008). That is, the retrieval may provide a $D_{\mathrm{e}}$ corresponding to a prominent small crystal mode.

\subsection{Sensitivity to ice crystal shape}

As noted, we have assumed an ice particle mass-dimension relationship based on 2D-S measurements taken during the TC4 campaign. The IWCs predicted by this relationship agree well with those measured directly by the counterflow virtual impactor (CVI) instrument during TC4. To test the retrieval's sensitivity to ice particle shape, we changed this mass-dimension power law so that the ice particle mass for any given size was $50 \%$ higher and $50 \%$ lower than normally predicted. This resulted in a $43 \%$ decrease and a $70 \%$ increase in the retrieved liquid fraction at $-22^{\circ} \mathrm{C}$, respectively.

Given the uncertainties in $\bar{d}, v$ and crystal shape, one could combine plausible values of these properties, such that the observed increase in $\beta_{\text {eff }}$ at warmer temperatures in Fig. 5 could be explained by all-ice conditions. However, the values chosen would not be supported by our best estimates of 


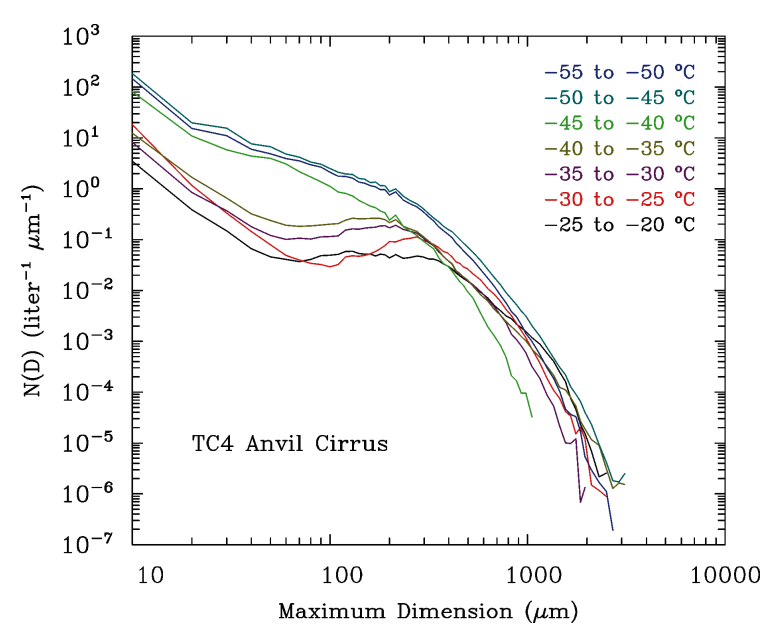

Fig. 11. Mean PSD (averaged over intervals of $5^{\circ} \mathrm{C}$ ) from "fresh" anvil cirrus sampled during TC4.

these properties, nor would the retrieved ice-only $\beta_{\text {eff }}$ values be consistent with the $\beta_{\text {eff }}$ derived from the PSD in situ measurements described below.

\subsection{Comparison of retrieved and measurement-derived $\beta_{\text {eff }}$}

Using all the TC4 PSD for anvil cirrus described in Jensen et al. (2009) and Lawson et al. (2010), $\beta_{\text {eff }}$ was calculated directly from these measurements of PSD concentration, area and mass (Mitchell et al., 2011b) using both MADA and the ice crystal optical properties of Yang et al. (2005), as shown in Fig. 12. The Yang et al. (2005) optical properties were calculated using the measured PSD concentration, area and mass as described in Mitchell et al. (2011b). For allice clouds, $\beta_{\text {eff }}$ is primarily the result of tunneling contributions that depend on particle size and shape (Mitchell et al., 2010). For a given PSD, the $\beta_{\text {eff }}$ differences in Fig. 12 reflect differences in tunneling contributions. For the Yang et al. optical properties, tunneling is greatest for quasi-spherical ice particles (droxtals) and less for bullet rosettes (Mitchell et al., 2006), while the MADA treatment assumes tunneling efficiencies of 0.9 and 0.4 for the small and large particle modes of the PSD. For $T<-40^{\circ} \mathrm{C}$, only ice exists and a direct comparison can be made between retrieved and PSD-

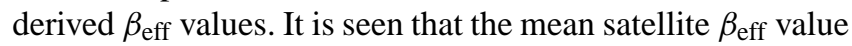
corresponds to quasi-spherical particles. This is consistent with the measured properties of TC4 cold anvil cirrus particles (Mitchell et al., 2010, 2011b). For $T>-40^{\circ} \mathrm{C}, \beta_{\text {eff }}$ for droxtals is between 1.042 and 1.022, slightly lower than our retrieved ice-only $\beta_{\text {eff }}$ value of $\sim 1.05$. This is possibly due to the deeper clouds sampled by aircraft having broader PSD relative to the thin cirrus retrieved.

The main point here is that these measurement-derived $\beta_{\text {eff }}$ values do not support the postulate that the increase in $\beta_{\text {eff }}$ in Fig. 5 for $T>-40^{\circ} \mathrm{C}$ is due to changes in ice crystal habit.

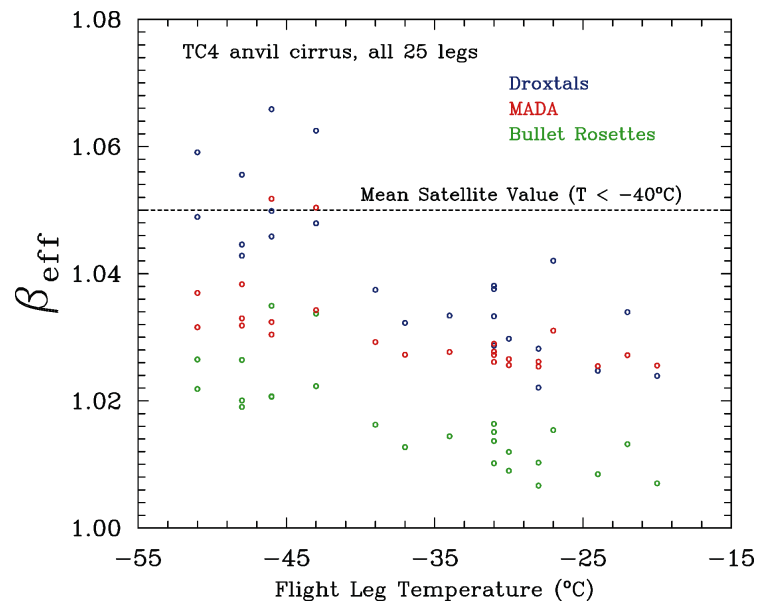

Fig. 12. Calculations of $\beta_{\text {eff }}$ from TC4 in situ measurements of fresh anvil cirrus using two ice optics schemes: MADA and Yang et al. (2005) (i.e., droxtals and bullet rosettes). The satellite-retrieved mean value of $\beta_{\text {eff }}$, based on this study for $T<-40^{\circ} \mathrm{C}$, is shown by the dashed line. A direct comparison between retrieved and measured $\beta_{\text {eff }}$ can be made for $T<-40^{\circ} \mathrm{C}$, suggesting quasi-spherical particles (i.e., droxtals) dominate, which was validated via in situ measurements.

That is, the measurement-derived $\beta_{\text {eff }}$ values that consider ice particle shapes likely to be present for $T>-40^{\circ} \mathrm{C}$ are

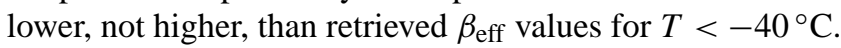

\subsection{Vertical phase partitioning}

Having the upper cloud layer composed mostly of liquid water, with the bottom layer mostly ice (e.g., Ansmann et al., 2009), or vice-versa, should not affect this retrieval significantly since only cloudy pixels with $\varepsilon(11 \mu \mathrm{m}) \leq 0.70$ were analyzed. The semi-transparent nature of such clouds ensures that at least some of the upwelling energy flux originated from the lowest cloud levels. Since all cloud levels contribute to the satellite-observed radiance, these retrievals yield an integrated assessment of liquid fraction throughout the cloud layer.

\subsection{CALIPSO retrievals}

The MODIS scenes used here are from the AQUA satellite, part of the A-train constellation of satellites. The CALIPSO satellite is also part of the A-train, and the CALIPSO lidar (CALIOP) is used to discriminate the thermodynamic phase of the underlying clouds, based on the algorithm of $\mathrm{Hu}$ et al. (2009). Phase discrimination is based primarily on lidar depolarization ratios since backscattered light from ice crystals is depolarizing, while backscattered light from liquid water droplets has minimal depolarization. However, horizontally oriented ice particles exhibit relatively weak depolarization, similar to liquid water clouds. The Hu et al. (2009) algorithm applies a spatial coherence analysis technique to 

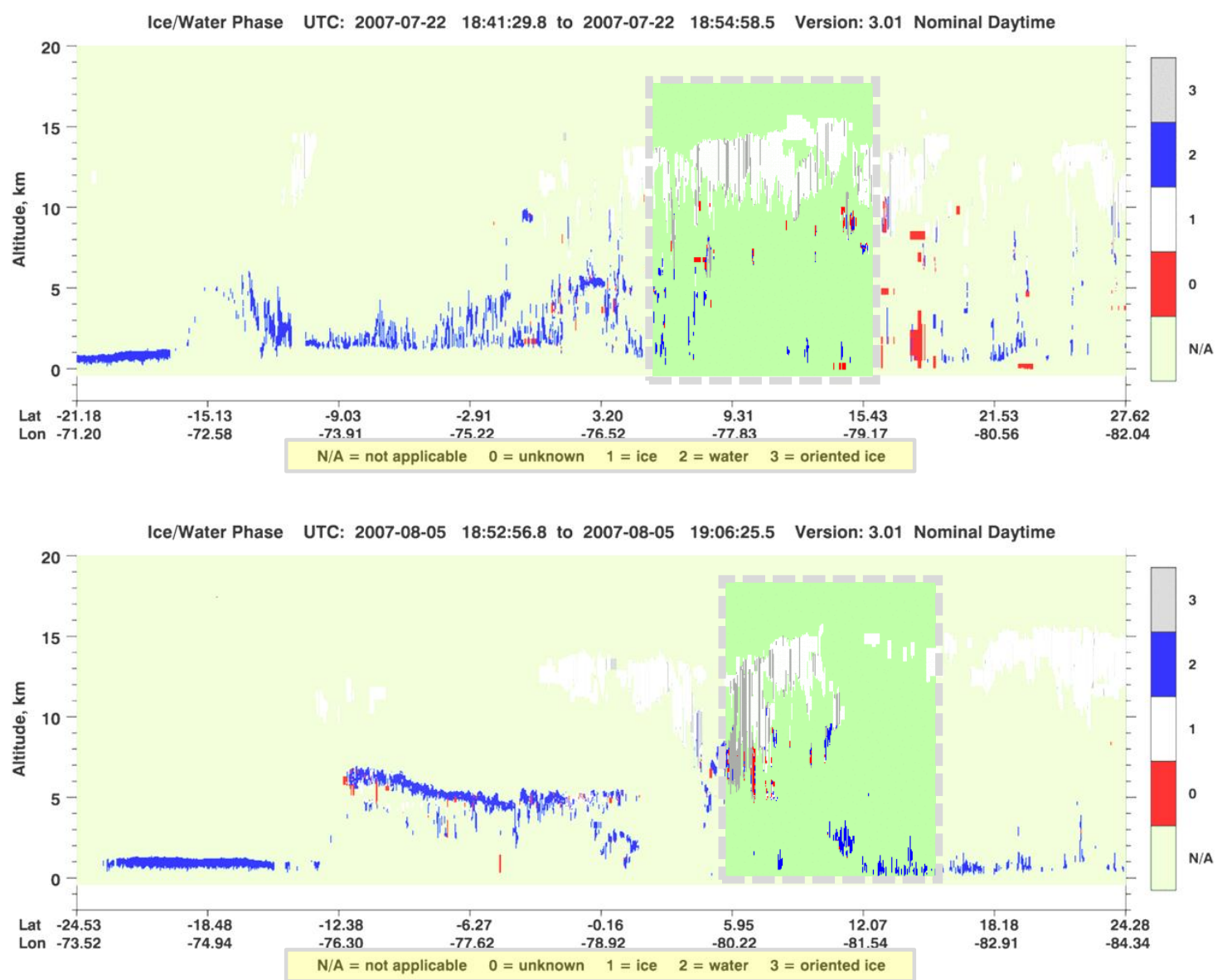

Fig. 13. CALIPSO/CALIOP discrimination of cloud phase for the two days studied here. The TC4 region considered in this study is bounded by the dashed box containing the green background. Blue and possibly red regions are dominated by liquid water. While coincident with MODIS sampling, the CALIPSO instrument samples only a narrow swath of the MODIS cloud scene due to the narrow field-of-view of the CALIOP lidar.

separate water clouds from ice clouds dominated by horizontally oriented particles. It thus discriminates well between liquid and ice clouds and also separates ice clouds into two categories, with and without a dominance of horizontally oriented ice particles.

The two CALIPSO/CALIOP cloud phase discrimination analyses coincident with the two MODIS scenes evaluated in this study are shown in Fig. 13, residing within the dashed boxes. Due to the narrow field-of-view of the CALIOP lidar, only a narrow path of clouds was sampled compared to the MODIS scenes. Nonetheless, the lidar analysis reveals the presence of liquid-dominated cloud under the CALIOP flight path corresponding to the two MODIS scenes, mostly between 7 and $9.5 \mathrm{~km}$. There is also a considerable amount of cloud classified as "unknown", which could be either liquid water or ice-dominated. Thus, the CALIOP phase analysis appears consistent with our column-integrated analysis for single-layer high clouds at various altitudes over ocean.

\section{Cloud optical property dependence on liquid fraction}

In addition to the liquid fraction, this algorithm also predicts the vertically integrated cloud effective diameter $D_{\mathrm{e}}$ that depends on both the liquid and ice phases. The effective diameter is defined here as

$D_{\mathrm{e}}=(3 / 2) \mathrm{TWC} /\left[\left(f_{\mathrm{i}} \rho_{\mathrm{i}}+f_{\mathrm{w}} \rho_{\mathrm{w}}\right) P_{\mathrm{t}}\right]$,

where TWC is the total water content, $\rho_{\mathrm{i}}$ is the density of bulk ice $\left(0.917 \mathrm{~g} \mathrm{~cm}^{-3}\right), \rho_{\mathrm{w}}$ is the density of bulk water $\left(1.0 \mathrm{~g} \mathrm{~cm}^{-3}\right), f_{\mathrm{i}}$ and $f_{\mathrm{w}}$ are the ice and liquid water fractions (relative to TWC), and $P_{\mathrm{t}}$ is the total projected area of the size distribution (including water and ice). This definition is universal for both water and ice clouds (Mitchell, 2002).

Shown in Fig. 14 is the $D_{\mathrm{e}}$ dependence on temperature for the cloud scene of 5 August 2007. The blue curve gives $D_{\mathrm{e}}$

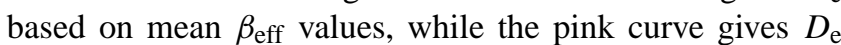
based on mean $\beta_{\text {eff }}+\sigma$ values. Since $D_{\mathrm{e}}$ is a measure of the cloud optical properties, this illustrates how $D_{\mathrm{e}}$ and hence optical properties are affected by low levels of liquid water 


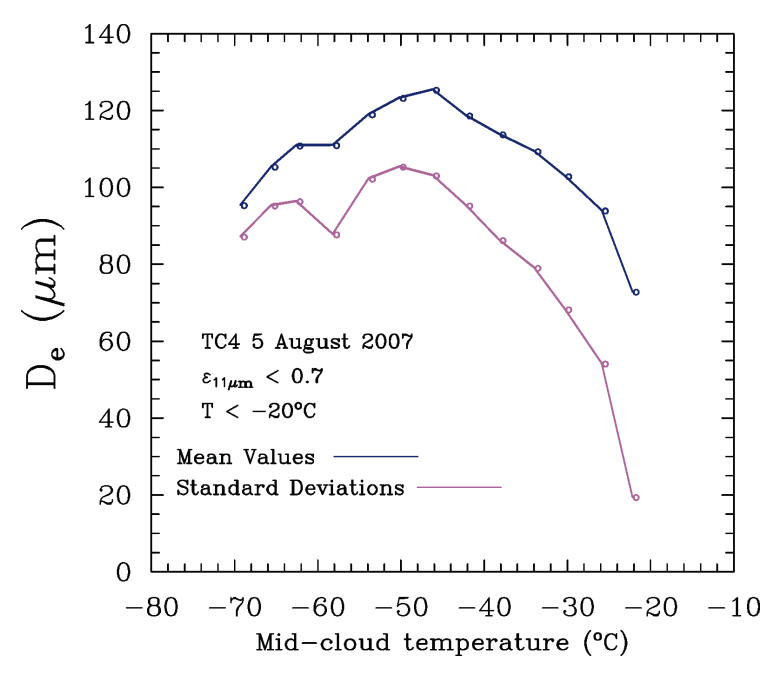

Fig. 14. Impact of the liquid fraction on the combined-phase effective diameter $D_{\mathrm{e}}$ corresponding to the means and standard deviations of $\beta_{\text {eff }}$, for the 5 August 2007 case study. The liquid fraction near $-22{ }^{\circ} \mathrm{C}$ is about $12 \%$.

in cloud fields that are primarily ice. Since the extinction coefficient at solar wavelengths can be expressed as

$\beta_{\mathrm{ext}} \approx 3 \mathrm{TWC} /\left(\rho D_{\mathrm{e}}\right)$

where $\rho$ is the weighted density shown in Eq. (11), it is evident that an increase in the mean liquid fraction from $0 \%$ to $12 \%$ (i.e., from -40 to $-22{ }^{\circ} \mathrm{C}$ ) results in a change in mean $D_{\mathrm{e}}$ from $\sim 113 \mu \mathrm{m}$ (pure ice cloud) to $73 \mu \mathrm{m}$, or an increase in extinction of $\sim 55 \%$ for constant TWC based on Eq. (12). Given that $2 / 3$ of the retrievals are contained in the mean $\pm \sigma$ range, the pink curve in Fig. 14 (corresponding to mean $\beta_{\text {eff }}+\sigma$ ) suggests that $16 \%$ of the clouds experience a change in $D_{\mathrm{e}}$ from $\sim 86 \mu \mathrm{m}$ to $\sim 20 \mu \mathrm{m}$ or less over this temperature range, which is over a four-fold increase in $\beta_{\text {ext }}$. It is therefore apparent that low levels of liquid water in clouds primarily containing ice need to be accounted for to accurately describe their radiative properties and the global radiation budget in general.

The cause of these low levels of liquid water between -38 and $-20^{\circ} \mathrm{C}$ is not clear, but high levels of sustained liquid water have been measured in deep tropical convection (Rosenfeld and Woodley, 2000), and liquid appears to dominate during the early development of tropical altocumulus and remains at the tops of such clouds in this temperature range (Ansmann et al., 2009). It is possible that gravity waves due to deep convection may be producing transient regions of liquid water. Clearly more research is needed in understanding the causes for liquid water in tropical clouds between -37 and $-20^{\circ} \mathrm{C}$. If indeed appreciable liquid water does exist in tropical cloud fields at these temperatures, such clouds will be susceptible to the first indirect aerosol effect since the liquid phase could dominate their optical properties.

\section{Summary and concluding remarks}

A new satellite remote sensing method has been described for retrieving the cloud temperature and emissivities in two split-window channels (11 and $12 \mu \mathrm{m})$. This differed from other studies in that all three of these properties were retrieved independently without estimating temperature from a nearby optically thick cloud evaluated as a "black body" emitter. This allowed the effective 12-to- $11 \mu \mathrm{m}$ cloud absorption optical thickness ratio, or $\beta_{\text {eff }}$, to be related to retrieved cloud temperature, revealing how cloud microphysical characteristics change with temperature. The satellite observations from this and another study (Giraud et al., 1997, 2001), which show $\beta_{\text {eff }}$ is approximately constant with temperature for all-ice conditions, provided a means for estimating the cloud liquid fraction as $\beta_{\text {eff }}$ increases for $T>-40^{\circ} \mathrm{C}$. Although uncertainties are large due to unknown parameters in the cloud droplet size distribution and ice particle shape, the retrievals do show the increasing likelihood of liquid water as temperatures increase between -40 and $-20^{\circ} \mathrm{C}$. Our best estimates for two MODIS tropical cloud scenes (where a cloud mask was applied to remove all clouds that did not appear to be cirrus) suggest the liquid fraction in both cases is around $10 \%$ on average for $T \approx-22{ }^{\circ} \mathrm{C}$. However, about $16 \%$ of the cloud pixels at this temperature appear to be liquid water dominated, and the individual pixel retrievals of $\beta_{\text {eff }}$ suggest that individual clouds tend to be either ice or liquid water dominated. To our knowledge, this type of information did not previously exist regarding widespread tropical cloud fields characterized by deep convection. However, a recent study by van Diedenhoven et al. (2012) describes a "liquid index" that was used to qualitatively assess the level of liquid water present in tropical clouds resulting from deep convection. Their results are qualitatively similar to those shown here.

In addition to these main results, this remote sensing method (when assuming all-ice conditions) predicts a change from mono-modal to bimodal ice size-spectra near $-40^{\circ} \mathrm{C}$ (bimodal for $T>-40^{\circ} \mathrm{C}$ ). This is what was observed from aircraft measurements of anvil cirrus (Mitchell et al., 2011a) and mid-latitude synoptic cirrus (Mitchell et al., 2011c) in the absence of liquid water, suggesting the retrieved change in modality could be partly due to the onset of homogeneous freezing nucleation. However, low levels of liquid may also be responsible for the retrieved $\beta_{\text {eff }}$ values. Indeed, the bimodality predicted by the retrieval between -30 and $-20^{\circ} \mathrm{C}$ appears too extreme to be attributed to the ice phase alone but is quite compatible with the presence of liquid water. Another interesting result was the consistency between the ice particle shapes observed during TC4 and those used in the retrieval to achieve consistency between retrieved and in situ measured $\beta_{\text {eff }}$ values. This result reinforces findings from in situ measurements, indicating that quasi-spherical and/or compact, high density ice particles dominated thin cirrus during TC4. 
Future work should refine this satellite retrieval by using in situ data from recent ice cloud field campaigns to better characterize cloud physical properties that pertain to the a priori retrieval assumptions (e.g., cloud droplet PSD mean size and dispersion, ice particle shape). These same in situ data could be used to test the retrieval when possible. This satellite retrieval could be applied to other types of cold cloudy environments to better characterize mixed phase conditions, provided the mean liquid fraction is less than $50 \%$. Aircraft measurements in mixed phase clouds show great variability in the liquid fraction from study to study (Korolev et al., 2003), making it difficult to determine the average and statistical behavior of the liquid fraction with temperature. But with satellite methods, this can potentially be done to some extent. This methodology could also be used to evaluate the impact of dust episodes on cloud glaciation and possibly other aspects of heterogeneous ice nucleation.

This methodology could be applicable to other satellite sensors with $\mathrm{CO}_{2}$ and thermal infrared window bands such as EOS AIRS or the Cross-track Infrared Sounder (CrIS) on the NPP satellite. The NOAA/NASA GOES-R satellite system will be launched in 2015 and will contain channels at 10.35, $11.2,12.3$ and $13.3 \mu \mathrm{m}$ having $2 \mathrm{~km}$ spatial resolution. It appears possible that some combination of these channels could be exploited as described here (albeit with more uncertainty in the temperature retrieval) to obtain time-dependent information on the phase composition of high clouds at a given location.

As mentioned, cloud phase information is sorely needed for testing the cloud parameterizations in climate models. For example, GCMs differ considerably in their albedo predictions from frontal cloud systems, and much of these differences were due to the treatment of cloud phase partitioning (Hu et al., 2010). One reason information about the liquid fraction is so crucial in high clouds is its large impact on the cloud optical properties, with a $10 \%$ liquid fraction increasing cloud optical thickness by more than $50 \%$ relative to all-ice conditions.

\section{Appendix A}

\section{Cloud-detection algorithm}

The MODIS 0.63, 0.86, 1.38, 11 and 14.2- $\mu$ m channel data were analyzed to screen for mainly ice-particle clouds and generate a cloud mask. By "mainly" here is meant that the dominant cloud-particle phase is ice. The premise of our study is that the observed cirrus radiative signatures in the split-window region can only be explained theoretically by the presence of some fraction of cloud liquid water. This cloud mask identifies such "cirrus" and excludes any thin cirrus, below which lay lower, purely water-droplet clouds. For this study, there are two single-channel threshold tests and an empirically based multi-layer cloud test.
The spectral tests are adapted from the heritage work of Saunders and Kriebel (1988). The first is a simple check on the magnitude of the $1.38-\mu \mathrm{m}$ reflectance, namely

$r_{1.38}>0.025$.

The 1.38- $\mu \mathrm{m}$ short-wave infrared channel is in the heart of a strong water-vapor absorption band. Any incident solarenergy flux traversing even a relatively moist atmosphere will be completely absorbed long before reaching the Earth's surface. However, at cirrus altitudes, water vapor is sparse enough so that the TOA-incident solar flux can reach the ice particles and be scattered spaceward without being absorbed. The result is that the Earth's surface and lower clouds are masked from view while the highly reflective cirrus ice particles contrast well with the homogeneously dark background.

The second test compares the $14.2-\mu \mathrm{m} \mathrm{CO} \mathrm{CO}_{2}$ absorptionband brightness temperature with a threshold:

$T_{14.2}<220 \mathrm{~K}$.

Deterministic reasoning for this test is similar to that for Eq. (A1): the Earth's surface and the lower and mid-level atmospheric regions are obscured from view in the $14.2-\mu \mathrm{m}$ channel by the strongly absorbing atmospheric carbon dioxide, providing a relatively uniform background against which the cold cirrus cloud particles contrast well.

In this study, we want to analyze only those pixels containing cirrus. However, some of the pixels flagged by the cloud tests Eqs. (A1) and (A2) detect cirrus with underlying water-droplet clouds. We developed an empirical test to distinguish these "multi-layer" and "single-layer" pixels. The test is based on the appearance of individual pixels in the visible/near-IR/thermal-infrared color composite, as shown in Fig. 3. First, a discussion is necessary on how the color composites were generated.

In these images, the red, green and blue intensities are driven by the MODIS radiance magnitudes in the visible blue $(0.47-\mu \mathrm{m})$, near-infrared $(0.86-\mu \mathrm{m})$ and thermal infrared $(11-\mu \mathrm{m})$ bands. A grayscale image is generated for each of these channels by mapping the observed minimum reflectance (maximum brightness temperature) to an 8-bit grayshade value of zero, and the maximum reflectance (minimum brightness temperature) to 255 . The color image is obtained when these three grayscale images drive the redgreen-blue (RGB) primary-color inputs of the composite. Combined in this way, open ocean appears black, low waterdroplet clouds bright yellow, cloud-free land green, thin cirrus clouds bluish, and multilayer clouds (ice over water) are a milky yellow.

The color of each composite pixel is determined by the relative strengths of the primary-color intensities. The overall intensity $I$ for each pixel is defined as

$I=(R+G+B) / 3$,

where $R, G$ and $B$ are the 8-bit intensities of the visible, nearIR and thermal infrared grayscale images, respectively. The 
milky-yellow color of the multilayer pixels is identifiable using the following logical threshold test:

$\{R>I$ or $G>I\}$ and $\{B<I\}$

for only those pixels that also pass the cloud test prescribed by Eq. (A1).

The cirrus pixels that pass these tests are passed along to the quantitative retrieval algorithms outlined in Sect. 2. These surviving pixels are also displayed in Fig. 4, which can be compared directly with the composite images of Fig. 3.

Acknowledgements. This research was primarily sponsored by the Office of Science (BER), US Dept. of Energy, Grant DE-FG0206ER64201. We also gratefully acknowledge the contributions of John Eylander at the US Air Force Weather Agency for supporting the development of the satellite-based emissivity retrievals. Additional support from NASA EPSCoR under Cooperative Agreement No. NNX10AR89A is gratefully acknowledged. We are grateful to Paul Lawson for providing the TC4 in situ data, and are grateful to the two anonymous reviewers for their constructive comments. This work began as a ground-based mixed-phase cloud retrieval study, but as research evolved it was apparent that the methodology was best suited for satellite remote sensing.

Edited by: P. Stammes

\section{References}

Ansmann, A., Tesche, M., Seifert, P., Althausen, D., Engelmann, R., Fruntke, J., Wandinger, U., Mattis, I., and Müller, D.: Evolution of the ice phase in tropical altocumulus: SAMUM lidar observations over Cape Verde, J. Geophys. Res., 114, D17208, doi:10.1029/2008JD011659, 2009.

Cooper, S. and Garrett, T.: Identification of small ice cloud particles using passive radiometric observations, J. Appl. Meteorol. Clim., 49, 2334-2347, 2010.

Curry, J. A., Rossow, W. B., Randall, D., and Schramm, J. L.: Overview of Arctic cloud and radiation characteristics, J. Climate, 9, 1731-1764, 1996.

Fleishauer, V., Larson, V. E., and Vonder Haar, T. H.: Observed microphysical structure of midlevel, mixed-phase clouds, J. Atmos. Sci., 59, 1779-1804, 2002.

Giraud, V., Buriez, J. C., Fouquart, Y., and Parol, F.: Large-Scale Analysis of Cirrus Clouds from AVHRR Data: Assessment of Both a Microphysical Index and the Cloud-Top Temperature, J. Appl. Meteorol., 36, 664-674, 1997.

Giraud, V., Thouron, O., Reidi, J., and Goloub, P.: Analysis of direct comparison of cloud top temperature and infrared split window signature against independent retrievals of cloud thermodynamic phase, Geophys. Res. Lett., 28, 983-986, 2001.

Heymsfield, A. J., Milosevich, L. M., Slingo, A., Sassen, K., and Starr, D. O'C.: An observational and theoretical study of highly supercooled altocumulus, J. Atmos. Sci., 48, 923-945, 1991.

Hobbs, P. V. and Rangno, A. L.: Ice particle concentrations in clouds, J. Atmos. Sci., 42, 2523-2549, 1985.
Hobbs, P. V. and Rangno, A. L.: Microstructures of low and middlelevel clouds over the Beaufort Sea, Q. J. Roy. Meteor. Soc., 124, 2035-2071, 1998

Hu, Y., Winker, D., Vaughan, M., Lin, B., Omar, A., Trepte, C., Flittner, D., Yang, P., Nasiri, S. L., Baum, B., Holz, R., Sun, W. Liu, Z., Wang, Z., Young, S., Stamnes, K., Huang, J., and Kuehn, R.: CALIPSO/CALIOP cloud phase discrimination algorithm, J. Atmos. Ocean. Tech., 26, 2293-2309, 2009.

Hu, Y., Rodier, S., Xu, K.-M., Sun, W., Huang, J., Lin, B., Zhai, P., and Josset, D.: Occurrence, liquid water content, and fraction of supercooled water clouds from combined CALIOP/IIR/MODIS measurements, J. Geophys. Res., 115, D00H34, doi:10.1029/2009JD012384, 2010.

Inoue, T.: On the temperature and emissivity determination of semitransparent cirrus clouds by bispectral measurements in the $10 \mu \mathrm{m}$ window region, J. Meteorol. Soc. Jpn., 63, 88-98, 1985.

Ivanova, D.: Cirrus clouds parameterization for global climate models (GCMs) and North American (Mexican) monsoon modeling study, Ph.D. dissertation, University of Nevada, Reno, 181 pp., 2004.

Jensen, E. J., Lawson, P., Baker, B., Pilson, B., Mo, Q., Heymsfield, A. J., Bansemer, A., Bui, T. P., McGill, M., Hlavka, D., Heymsfield, G., Platnick, S., Arnold, G. T., and Tanelli, S.: On the importance of small ice crystals in tropical anvil cirrus, Atmos. Chem. Phys., 9, 5519-5537, doi:10.5194/acp-9-5519-2009, 2009.

Korolev, A. V., Isaac, G. A., Cober, S. G., Strapp, J. W., and Hallett, J.: Microphysical characterization of mixed phase clouds, Q. J. Roy. Meteor. Soc., 129, 39-65, 2003.

Lawson, R. P., Baker, B. A., Schmitt, C. G., and Jensen, T. L.: An overview of microphysical properties of Arctic clouds observed in May and July 1998 during FIRE ACE, J. Geophys. Res., 106, 14989-15014, 2001.

Lawson, R. P., Jensen, E., Mitchell, D. L., Baker, B., Mo, Q., and Pilson, B.: Microphysical and radiative properties of tropical clouds investigated in TC4 and NAMMA, J. Geophys. Res., 115, D00J08, doi:10.1029/2009JD013017, 2010.

Li, Z.-X. and Le Treut, H.: Cloud-radiation feedbacks in a general circulation model and their dependence on cloud modeling assumptions, Clim. Dynam., 7, 133-139, 1992.

Matveev, L. T.: Cloud Dynamics, Atmospheric and Oceanic Sciences Library Series, D. Reidel, Vol. 2, p. 340, 1984.

Mitchell, D. L.: Parameterization of the Mie extinction and absorption coefficients for water clouds, J. Atmos. Sci., 57, 1311-1326, 2000.

Mitchell, D. L.: Effective diameter in radiation transfer: General definition, applications and limitations, J. Atmos. Sci., 59, 2330 2346, 2002.

Mitchell, D. L. and d'Entremont, R. P.: Satellite remote sensing of small ice crystal concentrations in cirrus clouds, Proc. 15th Int. Conf. on Clouds and Precipitation, Cancun, Mexico, ICCP, 185188, 2008.

Mitchell, D. L., Baran, A. J., Arnott, W. P., and Schmitt, C.: Testing and comparing the modified anomalous diffraction approximation, J. Atmos. Sci., 63, 2948-2962, 2006.

Mitchell, D. L., d'Entremont, R. P., and Lawson, R. P.: Inferring cirrus size distributions through satellite remote sensing and microphysical databases, J. Atmos. Sci., 67, 1106-1125, 2010. 
Mitchell, D. L., Mishra, S., and Lawson, R. P.: Representing the ice fall speed in climate models: Results from TC4 and ISDAC, J. Geophys. Res., 116, D00T03, doi:10.1029/2010JD015433, 2011a.

Mitchell, D. L., Lawson, R. P., and Baker, B.: Understanding effective diameter and its application to terrestrial radiation in ice clouds, Atmos. Chem. Phys., 11, 3417-3429, doi:10.5194/acp11-3417-2011, $2011 \mathrm{~b}$.

Mitchell, D. L., Mishra, S., and Lawson, R. P.: Cirrus Clouds and Climate Engineering: New Findings on Ice Nucleation and Theoretical Basis, Planet Earth 2011 Global Warming Challenges and Opportunities for Policy and Practice, edited by: Carayannis, E. G., available at: http://www.intechopen.com/articles/show/title/cirrus-cloudsand-climate-engineering-new-findings-on-ice-nucleation-andtheoretical-basis (last access: 16 December 2011), InTech, ISBN 978-953-307-733-8, 2011c.

Moncet, J.-L., Uymin, G., Alan, E., Lipton, A. E., and Snell, H. E.: Infrared Radiance Modeling by Optimal Spectral Sampling, J. Atmos. Sci., 65, 3917-3934, 2004.

Nalli, N. R., Minnett, P. J., and van Delst, P.: Emissivity and reflection model for calculating unpolarized isotropic water surfaceleaving radiance in the infrared. I: Theoretical development and calculations, Appl. Optics, 47, 3701-3721, 2008.

Parol, F., Buriez, J. C., Brogniez, G., and Fouquart, Y.: Information content of AVHRR channels 4 and 5 with respect to the effective radius of cirrus cloud particles, J. Appl. Meteorol., 30, 973-984, 1991.

Pinto, J. O., Curry, J. A., and Intrieri, J. M.: Cloud-aerosol interactions during Autumn over Beaufort Sea, J. Geophys. Res., 106, 15077-15097, 2001.

Pollack, J. B. and Cuzzi, J. N.: Scattering by non-spherical particles of size comparable to a wavelength: A new semi-empirical theory and its application to tropospheric aerosols, J. Atmos. Sci., 37, 868-881, 1980.

Rosenfeld, D. and Woodley, W.: Deep convective clouds with sustained supercooled liquid water down to $-37.5^{\circ} \mathrm{C}$, Nature, 405 , 440-442, 2000.

Saunders, R. W. and Kriebel, K. T.: An improved method for detecting clear-sky and cloudy radiances from AVHRR data, Int. J. Remote Sens., 9, 123-150, 2008.
Shupe, M. D. and Intrieri, J. M.: Cloud radiative forcing of the Arctic surface: The influence of cloud properties, surface albedo and solar zenith angle, J. Climate, 17, 616-628, 2004.

Shupe, M. D., Kollias, P., Matrosov, S. Y., and Schneider, T. L.: Deriving mixed-phase cloud properties from Doppler radar spectra, J. Atmos. Ocean. Tech., 21, 660-670, 2004.

Turner, D. D.: Arctic mixed-phase cloud properties from AERI lidar observations: Algorithm and results from SHEBA, J. Appl. Meteor., 44, 427-444, 2005.

van de Hulst, H.: Light Scattering by Small Particles, Dover, 470 pp., 1981.

van Diedenhoven, B., Fridlind, A. M., Ackerman, A. S., and Cairns, B.: Evaluation of hydrometeor phase and ice properties in cloudresolving model simulations of tropical deep convection using radiance and polarization measurements, J. Atmos. Sci., online first: doi:10.1175/JAS-D-11-0314.1, 2012.

Warren, S. G., Hahn, C. J., London, J., Chervin, R. M., and Jenne, R. L.: Global distribution of total cloud cover and cloud type amounts over land, NCAR Tech. Note 273+STR, NCAR Boulder, CO, 29 pp. + 200 maps, 1986.

Yang, P., Wei, H., Huang, H.-L., Baum, B. A., Hu, Y. X., Kattawar, G. W., Mishchenko, M. I., and Fu, Q.: Scattering and absorption property database for nonspherical ice particles in the near- through far-infrared spectral region, Appl. Optics, 44, 5512-5523, 2005.

Yoshida, R., Okamoto, H., Hagihara, Y., and Ishimoto, H.: Global analysis of cloud phase and ice crystal orientation from Cloud-Aerosol Lidar and Infrared Pathfinder Satellite Observation (CALIPSO) data using attenuated backscattering and depolarization ratio, J. Geophys. Res., 115, D00H32, doi:10.1029/2009JD012334, 2010.

Zhao, M. and Wang, Z.: Comparison of Arctic clouds between ECMWF simulations and ACRF long-term observations at the NSA Barrow site, J. Geophys. Res., 115, D23202, doi:10.1029/2010JD014285, 2010.

Zhao, Y., Mace, G., and Comstock, J.: The occurrence of particle size distribution bimodality in middle latitude cirrus as inferred from ground-based remote sensing data, J. Atmos. Sci., 68, 1162-1177, doi:10.1175/2010JAS3354.1, 2011. 